\title{
Intellectual Structure and Scientific Evolution of Strategic Decision in the Field of Business and Management (1971 to 2018)
}

\author{
Harry Patria*, Sari Wahyuni and Ratih Dyah Kusumastuti
}

\begin{abstract}
Manuscript type: Review paper

Research aims: This study aims to analyse the published works of strategic decision in business and management which have had the greatest impact and evolutionary scientific trend within the intellectual sphere. Drawing from the integrative perspective, this study attempts to: (i) investigate the intellectual structure of earlier works so as to analyse the evolution of strategic decisions; (ii) examine the evolutionary scientific trends, and (iii) identify some implications for future research in this area.

Design/Methodology/Approach: This study generates its analysis based on the following bibliometric tools: (i) multidimensional data analysis using the Sankey Diagram, (ii) visual network and heat map analysis using the VOSviewer, and (3) strategic diagrams and evolution maps using the SciMAT. The methodology is based on the bibliometric technique of citation and co-citation analyses which are scientifically applied to a sample of 1,218 articles published in leading management and business journals over a period of 48 years, from 1971 to 2018.
\end{abstract}

* Corresponding author: Harry Patria is a Doctoral candidate at the Graduate School of Management, Faculty of Economic and Business, Universitas Indonesia, Indonesia. E-mail: harpatria@gmail.com

Sari Wahyuni is an Associate Professor at the Department of Management, Faculty of Economic and Business, Universitas Indonesia, Indonesia. E-mail: sari.wahyuni@ui.ac.id Ratih Dyah Kusumastuti is an Assistant Professor at the Department of Management, Faculty of Economic and Business, Universitas Indonesia, Indonesia. E-mail: ratih.dyah@ui.ac.id

Acknowledgement: The authors would like to express their gratitude to the Indonesia Endowment Fund for Education (Lembaga Pengelola Dana Pendidikan/LPDP), Ministry of Finance of Indonesia for facilitating the doctoral scholarship and this research project.

https:// doi.org/10.22452/ajba.vol12no2.9 
Research findings: The findings of this study plots the intellectual structure of the strategic decision as well as the evolutionary themes of the strategic decisions, for instance, decision-making and intuition (2000-2004), bounded rationality and uncertainty (2005-2009), decision support system and artificial intelligence (2010-2014), and decisionmaking and intuition (2015-2019). Overall, the results demonstrate the top scientific themes that were prevalent over a period of 48 years. The themes include: decision-making, intuition, rationality, behavioural economics, bounded rationality and investment decision. Theoretical contribution/Originality: These findings provide valuable insights which demarcate the evolution of strategic decision as viewed through the synoptic-incremental continuum of rationality, intuition and political decision process. This study also contributes to the emerging role of behavioural economics on the strategic decisionmaking process in business and management. The results also highlight the role of the incremental decision process as an intuitive and political decision that can be interactively enhanced by decisionmakers while under increased risk and uncertainty.

Practitioner/Policy implications: The results of this study suggest that decision-makers need to pay attention towards building and developing the incremental process such as intuitive and political decision along with rationality so as to optimise the decision outcomes.

Keywords: Strategic Decision, Decision-Making, Bibliometric Review, Business, Management, Intuition, Rationality

JEL Classification: M10, Y3

\section{Introduction}

The past few decades have seen the proliferation of research on strategic decisions (SD) in the field of business and management (Eisenhardt \& Zbaracki, 1992; Elbanna, 2006; Ireland \& Miller, 2004; Papadakis, Lioukas, \& Chambers, 1998; Rajagopalan, Rasheed, \& Datta, 1993). The concept of SD has proven to be an interdisciplinary field of research even from the beginning, whether from psychology, organisation or strategic management (Eisenhardt \& Zbaracki, 1992; Papadakis et al., 1998). Given its relevance, research on SD seems to have flourished as the field of study evolved (Dean \& Sharfman, 1996; Eisenhardt \& Zbaracki, 1992; Fahey, 1981; Mintzberg, Raisinghani, \& Theoret, 1976).

One of the most important agenda for advancing a particular state of the art in business and management is to synthesise the interdisciplinary research findings (Zupic \& Čater, 2015). In general, 
researchers have commonly applied two traditional techniques to make sense of the earlier findings - the qualitative approach of a structured literature review (Schmidt, 2008; Zupic \& Čater, 2015), and the quantitative method of meta-analysis (Eisenhardt \& Zbaracki, 1992; Elbanna, 2006; Rajagopalan et al., 1993; Steptoe-Warren, Howat, \& Hume, 2011). Typically, these studies are considered as having adopted the impressionist approach while their findings tended to reflect the subjective views of the authors (Ramos-Rodríguez \& RuízNavarro, 2004). Such findings, and their strategic implications were also instinctively determined by the authors, hence they often lack rigour and scientific legitimacy (Tranfield, Denyer, \& Smart, 2003). In addition, those types of narrative literature review also carry some degrees of limitation especially those involving longitudinal cases conducted over a long period of time. Consequently, caution should be applied when interpreting the results, except for a few exceptions (BlancoMesa, Merigo, \& Gil-Lafuente, 2017; Bragge, Korhonen, Wallenius, \& Wallenius, 2010; Qaiser, Ahmed, Sykora, Choudary, \& Simpson, 2017; Yu, Wang, Zhang, \& Zhang, 2018). Thus far, existing studies have not been able to indicate with details, how research on SD had evolved over the years, which this study aims to address.

Reviews of literature had, to some extent applied the bibliometric technique as a quantitative approach to unravel the systematic and rigorous process of refining the quality of the review (Zupic \& Čater, 2015). Over time, the bibliometric databases encompassing Scopus or Web of Science, and the various bibliometric tools such as the VOS viewer, and the SciMAT, had attracted much attention. These bibliometric methods have been consistently employed to explore the intellectual structure of strategic management (Ferreira, Fernandes, \& Ratten, 2016; Nerur, Rasheed, \& Natarajan, 2008; Ramos-Rodríguez \& Ruíz-Navarro, 2004; Ronda-Pupo \& Guerras-Martin, 2012). Earlier bibliometric literature had mainly focussed on fuzzy decision making (Blanco-Mesa et al., 2017), multiple criteria decision making (Bragge et al., 2010; Yu et al., 2018), and the decision support system (Qaiser et al., 2017). Seminal bibliometric analyses have been used by scholars (Yu et al., 2018; Blanco-Mesa et al., 2017; Ferreira et al., 2016; SteptoeWarren et al., 2011; Elbanna \& Younies, 2008; Rajagopalan et al., 1993) to review literature on SD. However, digressing slightly from this, the current review aims to provide a perspective of the continuity, and a more updated and integrative point of view on the research on SD, as compiled from past studies. 
In this regard, the objectives of this study are to: (i) investigate the intellectual structure noted in earlier studies so as to analyse the evolution of the research on SD; (ii) examine the evolutionary scientific trends; and (iii) identify some implications for future research in this area. The contributions derived from this study will help to address the literature gap left by earlier conventional literature on SD research, given the development that had flourished in this area. The questions this study aims to address are: What are the main scientific themes previously noted in SD literature? Who among the authors were the most persuasive? Which was the most dominant paper? and What was the most influential paper? The answers derived for these questions will contribute to a deeper understanding of the SD evolution. Such research profiling analyses have been extensively applied to enrich traditional literature reviews (Bragge et al., 2010; Zupic \& Čater, 2015).

This study contributes to the field of business and management in a number of ways. First, it highlights the main clusters of SD. Second, it identifies the most highly cited scientific themes and their interdependencies in the given period within 48 years. These themes include: decision-making and intuition (2000-2004), bounded rationality and uncertainty (2005-2009), decision support system and artificial intelligence (2010-2014), followed by decision-making and intuition (2015-2019). Earlier bibliometric works had focussed on a short time period (Ferreira et al., 2016). Therefore, by analysing previous studies over a long-time frame, the gaps left unattended by previous bibliometric works would be able to shed light on the areas that need to be attended. Further, the findings would also be able to emphasise on how the SD research field may further evolve in the future (Ferreira et al., 2016).

The remainder of this paper is organised as follows. Section 2 examines the conceptual background of SD in the field of business and management. Section 3 discusses the bibliometric methods. Section 4 presents the findings of the analysis. Section 5 draws on the conclusion and Section 6 provides the recommendation for future research.

\section{Strategic Decision: Conceptual Background}

Prior to performing the bibliometric analyses, we need to identify the underlying concept of strategic decision in this study. In accordance with the works of prolific scholars (Bourgeois \& Eisenhardt, 1988; Dean \& Sharfman, 1993; Eisenhardt \& Zbaracki, 1992; Elbanna, 2006; Kahneman \& Tversky, 1979; Mintzberg et al., 1976; Papadakis et al., 
1998; Rajagopalan et al., 1993; Sadler-smith, Hodgkinson, \& Sinclair, 2008; Simon, 1987), the ontological and epistemological differences in the selected publications were discussed using a synoptic-incremental continuum. Elbanna (2006) had reviewed seminal works on the SD process which include the rational, intuitive and political process.

The rational process focuses on how decisions can be divided into structured decision problems which can be solved by collecting and analysing specific information (Dean \& Sharfman, 1993, 1996), applying certain analytic tools (Dean \& Sharfman, 1996), generating alternatives and new aspects (Eisenhardt, 1989), defining goals and priorities as the decision criteria, and thinking about the alternatives and consequences (Dean \& Sharfman, 1996). The intuitive process, in comparison, concentrates on the unconscious or subconscious processes and spontaneous manners by applying personal judgments (Khatri \& $\mathrm{Ng}$, 2000), gut feelings or hunches (Dane \& Pratt, 2007; Hodgkinson, Langan-fox, \& Sadler-smith, 2008; Hodgkinson, Sadler-Smith, Burke, Claxton, \& Sparrow, 2009; Khatri \& Ng, 2000), past experiences (Dane \& Pratt, 2007), and heuristics (Bingham \& Eisenhardt, 2011; Keats, 1991; Miller \& Shapira, 2004). The political process looks at the social aspects when decision makers interact with one another in the social context by exercising their respective power and status so as to enforce decisions, to negotiate, or to bargain with others, to form alliances to effectuate certain interests, and to prioritise personal and group goals over organisational goals (Bourgeois \& Eisenhardt, 1988; Dean \& Sharfman, 1993, 1996; Elbanna \& Child, 2007; Papadakis et al., 1998).

The rational perspective, also termed as the synoptic perspective, relies on the first stage of the rational process, whereas the incrementalpolitical perspective focusses on the other two decision processes mentioned (Elbanna \& Child, 2007). Most literature and practices tend to emphasise on the rational rather than the incremental-political perspective. Khatri and Ng (2000) help to explain. They had noted that many scholars and practitioners held the belief that intuitive processes were beyond rationality, hence out of the scope of scientific studies. In fact, "gut-feeling" is actually a sub-conscious derivative of the accumulation of years of management, experience and knowledge while the intuitive process is derived from personal experiences, tacit knowledge and learning (Baldacchino, Ucbasaran, \& Cabantous, 2014; Brockmann \& Simmonds, 1997; Isenberg, 1986; Khatri \& Ng, 2000; Simon, 1987).

Based on this interdisciplinary study, it appears that much of the work in SD showed that there was no single discipline covering 
all aspects of the strategic decision process. The decision process had moved from rationality to incrementalism such as intuition and political processes. Of the many authors who were involved with SD in business and management, the most influential were listed as Akinci and Sadlersmith (2012). They had dedicated their works to the "conscious and nonconscious process". In another study, Kahneman and Tversky (1979) dedicated their work to the "heuristics and biases", while Mintzberg et al. (1976), Eisenhardt and Zbaracki (1992), and Dean and Sharfman (1996) were the pioneers of the research on strategic decision. Following this, Epstein (1985) proposed the cognitive-experiential self-theory and Simon (1987) established the concept of bounded rationality. Klein (1998) focussed on "naturalistic decision-making", Sadler-smith and Shefy (2004) stressed on gut feelings and Dean and Sharfman (1993) followed by Elbanna $(2006,2018)$ emphasised on political decisions.

To deepen the diverse perspectives, there has been recourse to combining diverse fields such as the rational, intuitive and political decision process as an option to generate the integrative approach for the various domains of SD. Following previous seminal literature (Dean \& Sharfman, 1996; Elbanna, 2006, 2018; Elbanna, Kapoutsis, \& Mellahi, 2017), this study also applies the integrative perspective for addressing the coexistence of the synoptic and incremental perspective on the SD making process. To determine the scope and validity of the bibliometric analysis conducted, this study also applies the inclusion and exclusion criteria. They are systematically defined and then applied. The eligibility criteria was then utilised to identify the appropriate literature. In line with the conceptual background and objective of this study, the inclusion criteria was based on past articles found and indexed by Scopus. The detailed technique depicting this inclusion criteria was explained using key terms, and the Boolean logic. In contrast, the exclusion criteria were derived from the contexts of particular fields of business and management research looking at SD. Further to the criteria, the period of publication dating from 1971 to 2018 was also added so as to exclude other publications that go beyond the selected period.

\section{Methods}

\subsection{Data Collection}

Taking into consideration the objectives of this study, a descriptive analysis of the articles selected were also undertaken. These were compiled from the online database performed by Scopus, dating back 
1971 to 2018. The multiple datasets comprised thousands of academic publications, and bibliographic datasets which included authors, citations and affiliations. These were gathered based on key terms, and the Boolean logic - "decision", "strategic decision", "decision-making", "rationality", "political decision", "intuition" or "political behaviour". These may appear either in the title, keywords or abstracts. As a matter of illustration, the current study was undertaken during the middle week of September 2018.

In this review, a total of 8,911 publications were generated. They were filtered by the field, "business and management" which served as the major area of this study. This led to a final total of 1,218 articles published in the period of 1971 to 2018. Data were collected using Scopus journals which were accessed through the University of Indonesia (http://remote-lib.ui.ac.id). Our search shows that the field of SD have attracted an increasing interest among researchers and practitioners. Figure 1 depicts the scientific evolution of SD which also highlights the total number of articles published. The figure also demonstrates that from the 1970s until the 1990s, publications were infrequent. An exponential growth was noted between 2005-2009 and 2010-2014 where publications peaked (314 and 348, respectively). The rate however, diminished in the subsequent period between 2015-2018 (only 281).

Table 1 summarises the most influential publication of SD in the field of business and management. In this section, the prolific articles

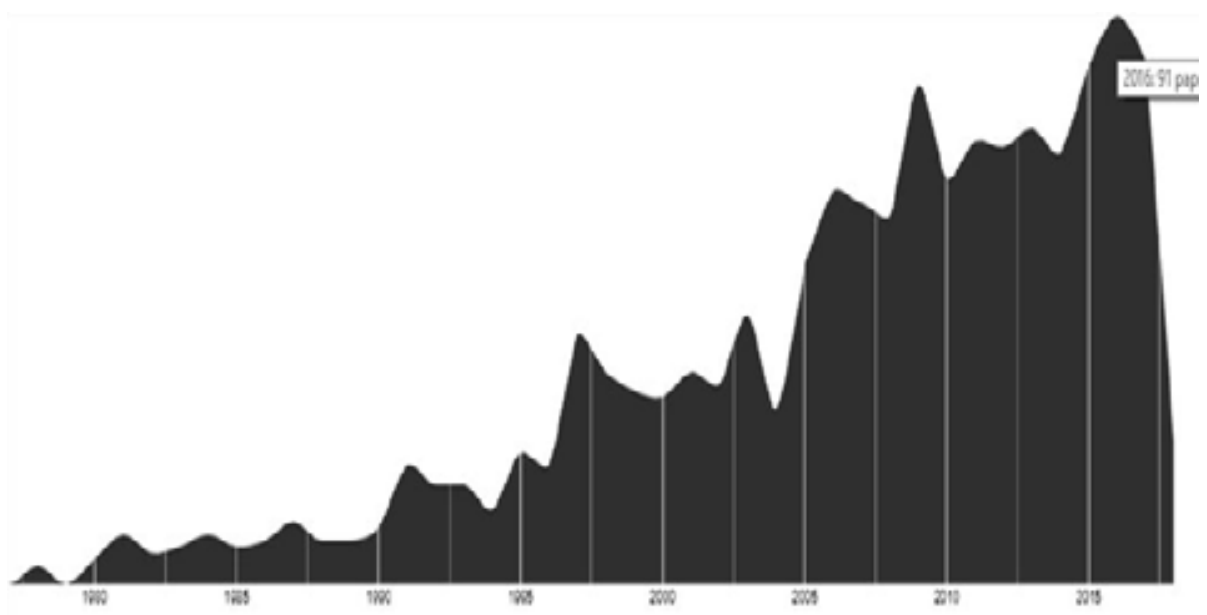

Figure 1: Number of Published Articles Each Year 
Table 1: Most Influential SD Publications in Business and Journals Reviewed

\begin{tabular}{|c|c|c|c|}
\hline Authors, Year & Title & Source title & $\mathrm{C}$ \\
\hline $\begin{array}{l}\text { Eisenhardt \& } \\
\text { Martin, } 2000\end{array}$ & $\begin{array}{l}\text { Dynamic capabilities: What are } \\
\text { they? }\end{array}$ & $\begin{array}{l}\text { Strategic Manage- } \\
\text { ment Journal }\end{array}$ & 4981 \\
\hline Amason, 1996 & $\begin{array}{l}\text { Distinguishing the effects ... } \\
\text { conflict on strategic decision ... }\end{array}$ & $\begin{array}{l}\text { Academy of Man- } \\
\text { agement Journal }\end{array}$ & 1124 \\
\hline $\begin{array}{l}\text { Lumpkin \& } \\
\text { Dess, } 2001\end{array}$ & $\begin{array}{l}\text { Linking two dimensions of } \\
\text { entrepreneurial ... }\end{array}$ & $\begin{array}{l}\text { Journal of Business } \\
\text { Venturing }\end{array}$ & 829 \\
\hline $\begin{array}{l}\text { Finkelstein, } \\
1992\end{array}$ & $\begin{array}{l}\text { Power in top management } \\
\text { teams ... }\end{array}$ & $\begin{array}{l}\text { Academy of Man- } \\
\text { agement Journal }\end{array}$ & 741 \\
\hline $\begin{array}{l}\text { Forbes \& } \\
\text { Milliken, } 1999\end{array}$ & $\begin{array}{l}\text { Cognition and corporate gover- } \\
\text { nance: ... strategic decision- } \\
\text { making groups ... }\end{array}$ & $\begin{array}{l}\text { Academy of } \\
\text { Management } \\
\text { Review }\end{array}$ & 736 \\
\hline Sarkis, 2003 & A strategic decision framework ... & $\begin{array}{l}\text { Journal of Cleaner } \\
\text { Production }\end{array}$ & 687 \\
\hline $\begin{array}{l}\text { Eisenhardt \& } \\
\text { Zbaracki, } 1992\end{array}$ & Strategic decision making & $\begin{array}{l}\text { Strategic Manage- } \\
\text { ment Journal }\end{array}$ & 628 \\
\hline $\begin{array}{l}\text { Swamidass \& } \\
\text { Newell, } 1987\end{array}$ & $\begin{array}{l}\text { Manufacturing strategy, } \\
\text { environmental uncertainty ... }\end{array}$ & $\begin{array}{l}\text { Management } \\
\text { Science }\end{array}$ & 615 \\
\hline $\begin{array}{l}\text { Dean \& } \\
\text { Sharfman, } 1996\end{array}$ & Does decision process matter? ... & $\begin{array}{l}\text { Academy of Man- } \\
\text { agement Journal }\end{array}$ & 449 \\
\hline $\begin{array}{l}\text { Lant, Milliken, } \\
\text { \& Batra, } 1992\end{array}$ & $\begin{array}{l}\text { The role of managerial learning } \\
\text { and interpretation in strategic } \\
\text { persistence ... }\end{array}$ & $\begin{array}{l}\text { Strategic Manage- } \\
\text { ment Journal }\end{array}$ & 449 \\
\hline
\end{tabular}

Note: $\mathrm{C}=$ number of citations.

with the largest number of citations are presented and the distribution of the paper sources in the given selected periods are analysed.

Table 2 highlights the distribution periods. In the first period (19701989), it seems obvious that Long Range Planning (9.3\%) had pioneered the SD field. This is trailed by Strategic Management Journal (9.3\%), and the Journal of Management $(6.7 \%)$, corresponding to 34.7 per cent of the total number of references encountered. In the second period (19901999), the Strategic Management Journal (7.4\%) dominated, followed by Decision Support Systems (4.6\%), Management Decisions (3.7\%), and 
Long Range Planning (3.7\%), corresponding to 50.7 per cent of the total number of references encountered. In the third period (2000-2004), a dramatic change had occurred when Management Science $(7 \%)$ emerged to be the top followed by Strategic Management Journal $(4.2 \%)$, and International Journal of Production Economics (2.3\%), corresponding to 62.4 per cent of the total number of references encountered. In the fourth period (2005-2009), Management Science (4.8\%) remained at the top while the International Journal of Production Economics (3.6\%) came second, trailed by the Journal of Business Research (2.5\%), and then the Strategic Management Journal (2.2\%), corresponding to 61.8 per cent of the total number of references encountered. In the fourth period (2010-2014), there was a substantial change. The International Journal of Production Research (3.2\%) moved to the top, trailed by earlier prominent journals, such as Management Decision (2.6\%), and the Journal of Cleaner Production (2.3\%), corresponding to 69.5 per cent of the total number of references encountered. In the final stage of the years (2015-2018), the Strategic Management Journal (5\%) had rebounded to be the top together with the Journal of Cleaner Production (5\%), trailed by Technology Forecasting and Social Changes (3.6\%), corresponding to 64.1 per cent of the total number of references encountered.

This dynamic change in the increased publications revealed the importance of the SD research, and its evolution over a long-time frame. In accordance with the previous literature on strategic management research (Ferreira et al., 2016; Ramos-Rodríguez \& Ruíz-Navarro, 2004), our findings found that the Strategic Management Journal was the most powerful reference for disseminating knowledge in the field of SD research.

Table 3 illustrates the number of publications. It appears that the Strategic Management Journal dominated the race, with a total of 59 references (4,981 cited references), trailed by Management Decision (54 references and 1,124 cited references), Long Range Planning (39 references and 829 cited references), Decision Support Systems (29 references and 1,119 cited references), International Journal of Production Economics (29 references and 1,039 cited references), Journal of Business Research (29 references and 538 cited references), Technological Forecasting and Social Change (27 references and 538 cited references), Journal of Cleaner Production (25 references and 1,701 cited references), Journal of Management (21 references and 1,586 cited references), Decision Sciences (21 references and 1,034 cited references), Journal of Management Studies (17 references and 1,203 cited references), 
Harry Patria, Sari Wahyuni and Ratih Dyah Kusumastuti

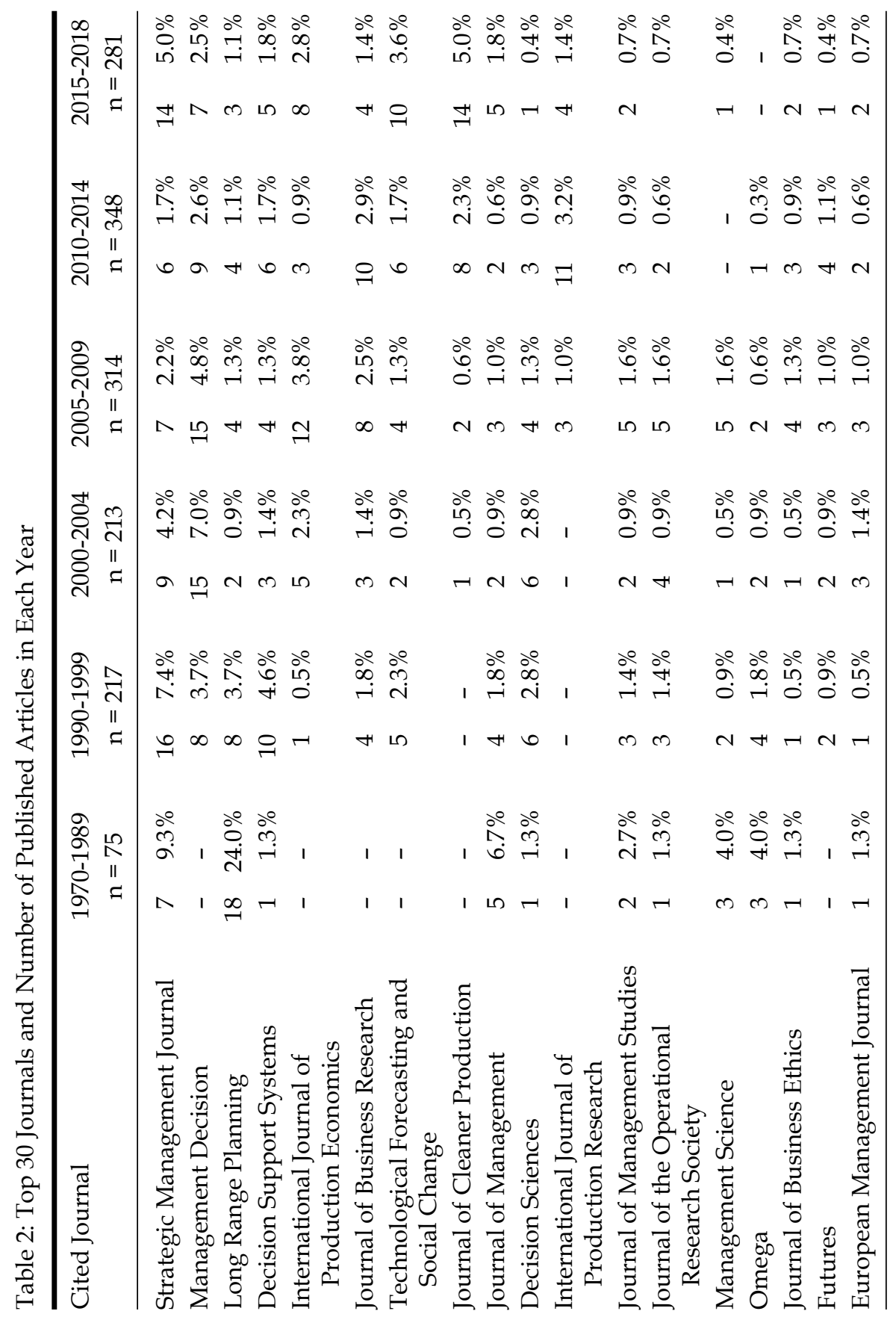


Intellectual Structure and Scientific Evolution of Strategic Decision in Business and Management

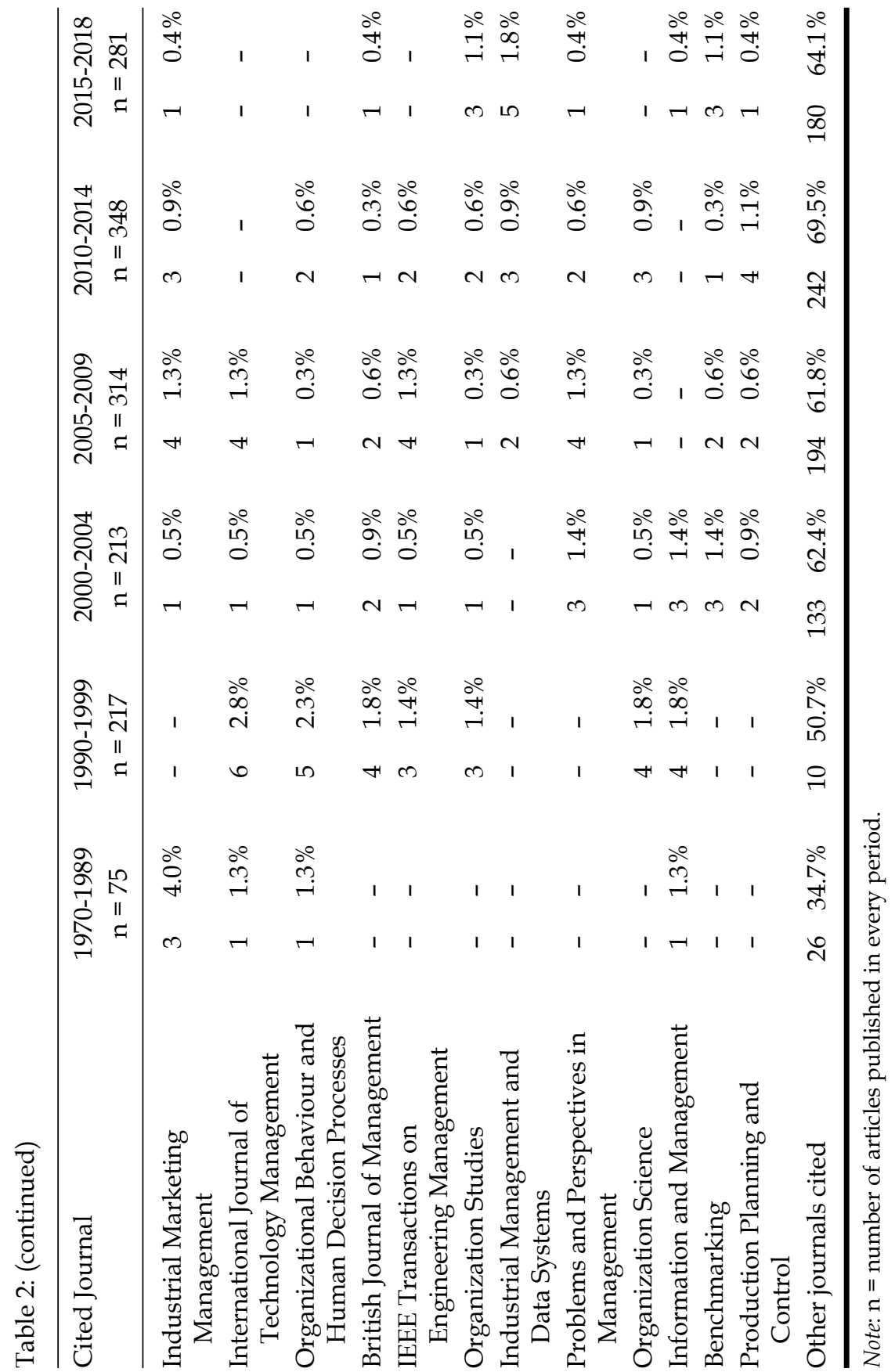


Table 3: Cited Journals, Index and Citations from 1971 to 2018

\begin{tabular}{|c|c|c|c|c|c|}
\hline Cited Journal & $\mathrm{n}$ & SJR'17 & H Index & $\mathrm{C}$ & $\mathrm{C} / \mathrm{n}$ \\
\hline Strategic Management Journal & 59 & 8.01 & 232 & 10,569 & 179 \\
\hline Management Decision & 54 & 5.36 & 209 & 915 & 17 \\
\hline Long Range Planning & 39 & 1.71 & 81 & 649 & 17 \\
\hline Decision Support Systems & 29 & 1.66 & 115 & 1,119 & 39 \\
\hline $\begin{array}{l}\text { International Journal of Production } \\
\text { Economics }\end{array}$ & 29 & 2.40 & 141 & 1,039 & 36 \\
\hline Journal of Business Research & 29 & 1.26 & 144 & 538 & 19 \\
\hline Technological Forecasting and Social Change & 27 & 1.38 & 86 & 538 & 20 \\
\hline Journal of Cleaner Production & 25 & 1.47 & 132 & 1,701 & 68 \\
\hline Journal of Management & 21 & 6.46 & 176 & 1,586 & 76 \\
\hline Decision Sciences & 21 & 1.38 & 93 & 1,034 & 49 \\
\hline International Journal of Production Research & 18 & 1.43 & 107 & 266 & 15 \\
\hline Journal of Management Studies & 17 & 3.80 & 145 & 1,203 & 71 \\
\hline Journal of the Operational Research Society & 15 & 1.00 & 87 & 158 & 11 \\
\hline Management Science & 12 & 5.36 & 209 & 1,210 & 101 \\
\hline Omega & 12 & 3.52 & 108 & 352 & 29 \\
\hline Journal of Business Ethics & 12 & 0.28 & 132 & 219 & 18 \\
\hline Futures & 12 & 1.23 & 66 & 170 & 14 \\
\hline European Management Journal & 12 & 1.26 & 84 & 157 & 13 \\
\hline Industrial Marketing Management & 12 & 1.66 & 106 & 150 & 13 \\
\hline $\begin{array}{l}\text { International Journal of Technology } \\
\text { Management }\end{array}$ & 12 & 0.41 & 48 & 55 & 5 \\
\hline $\begin{array}{l}\text { Organizational Behaviour and } \\
\text { Human Decision Processes }\end{array}$ & 10 & 1.99 & 122 & 430 & 43 \\
\hline British Journal of Management & 10 & 1.31 & 86 & 255 & 43 \\
\hline $\begin{array}{l}\text { IEEE Transactions on Engineering } \\
\text { Management }\end{array}$ & 10 & 0.73 & 80 & 247 & 25 \\
\hline Organization Studies & 10 & 0.02 & 120 & 239 & 24 \\
\hline Industrial Management and Data Systems & 10 & 0.90 & 81 & 61 & 6 \\
\hline Problems and Perspectives in Management & 10 & 0.14 & 14 & 11 & 1 \\
\hline Organization Science & 9 & 5.50 & 196 & 810 & 90 \\
\hline Information and Management & 9 & 1.63 & 135 & 208 & 23 \\
\hline Benchmarking & 9 & 0.56 & 49 & 190 & 21 \\
\hline Production Planning and Control & 9 & 1.26 & 61 & 138 & 15 \\
\hline
\end{tabular}

Note: $\mathrm{n}=$ number of articles published, $\mathrm{C}=$ number of citations, $\mathrm{C} / \mathrm{n}=$ number of citations per articles published, SJR = SCImago Journal Rank, $\mathrm{H}$ index $=$ an author-level metric in terms of productivity and citation impact. 
Journal of the Operational Research Society (15 references and 158 cited references), Management Science (12 references and 1,210 cited references), Omega (12 references and 352 cited references), Journal of Business Ethics (12 references and 219 cited references), Futures (12 references and 170 cited references), European Management Journal (12 references and 157 cited references), Industrial Marketing Management (12 references and 150 cited references), and the International Journal of Technology Management (12 references and 55 cited references). The 20 journals listed in the table provided a total of 467 articles, corresponding to 32.2 per cent of the total number of references encountered.

In accordance with previous literature which had performed bibliometric studies exceeding 40 years (Merigó, Pedrycz, Weber, \& de la Sotta, 2018), general indicators such as productivity and influence were measured. From a general point of view, productivity was commonly measured with the number of published articles while influence was assessed by the number of citations (Merigó et al., 2018). According to the productivity and influence analysis shown in Table 3, the Strategic Management Journal (59 references), Management Decision (54 references) and Long Range Planning (39 references) were considered the most productive journals over the given periods.

\subsection{Preliminary Analysis}

To assess the impact factor noted in previous studies (Ronda-Pupo \& Guerras-Martin, 2012), we also took into account these additional indicators. A preliminary study of the publications found that by far, the most frequently cited publication per paper (179) was the Strategic Management Journal. Despite having a relatively low number of published articles, the journal of Management Science (101) and Organization Science (90) earned second and third places, respectively.

Based on the keywords illustrated in Table 4, the key scientific words used were: 'strategic decision making' (163 occurrences), 'decision making' (150 occurrences), 'strategy' (44 occurrences), 'strategic management' (36 occurrences), 'strategic planning' (29 occurrences), 'corporate governance' (23 occurrences), 'strategic decisions' (17 occurrences), 'performance (16 occurrences), and 'competitive advantage' (12 occurrences). The common keywords used throughout the years were 'decision-making' and 'strategic decision making'. This finding also supports our selection for articles related to strategic decision making. Apart from the keywords generally related to decision-making, other 
Table 4: Top Scientific Keywords per Year

\begin{tabular}{|c|c|c|c|c|c|c|}
\hline Keywords & $\begin{array}{l}1995- \\
1999\end{array}$ & $\begin{array}{c}2000- \\
2004\end{array}$ & $\begin{array}{c}2005- \\
2009\end{array}$ & $\begin{array}{l}2010- \\
2014\end{array}$ & $\begin{array}{c}2015- \\
2018\end{array}$ & Total \\
\hline Activity-based costing & 2 & - & - & - & - & 2 \\
\hline Australia & 1 & - & - & - & - & 1 \\
\hline Benchmarking & - & 4 & - & - & - & 4 \\
\hline Case study & 1 & - & - & - & 2 & 3 \\
\hline China & - & - & - & 4 & - & 4 \\
\hline Cognition & 1 & - & - & 2 & - & 3 \\
\hline Evaluation & - & - & - & 3 & - & 3 \\
\hline Forecasting & - & 2 & - & - & - & 2 \\
\hline Framing & - & 2 & - & - & - & 2 \\
\hline Competitive advantage & 1 & 1 & 3 & 3 & 4 & 12 \\
\hline Consensus & 1 & - & - & - & - & 1 \\
\hline Corporate governance & - & 5 & 7 & 7 & 4 & 23 \\
\hline Corporate strategy & - & 3 & - & 3 & - & 6 \\
\hline Culture & 1 & - & - & - & - & 1 \\
\hline Customer satisfaction & - & - & 2 & - & - & 2 \\
\hline Data envelopment analysis & - & - & - & - & 3 & 3 \\
\hline Decision making & 15 & 24 & 48 & 48 & 15 & 150 \\
\hline Decision support systems & - & 4 & 5 & - & - & 9 \\
\hline Entrepreneurs & - & - & 2 & - & - & 2 \\
\hline Entrepreneurship & 1 & - & - & - & - & 1 \\
\hline Environmental scanning & - & 2 & - & - & - & 2 \\
\hline Executive information systems & 1 & - & - & - & - & 1 \\
\hline Firm performance & - & - & - & - & 2 & 2 \\
\hline Framing & 2 & - & - & - & - & 2 \\
\hline Governance & - & - & - & - & 3 & 3 \\
\hline Group support systems & 2 & - & - & - & - & 2 \\
\hline Human resource management & 1 & - & 2 & - & - & 3 \\
\hline India & - & - & - & 3 & 2 & 5 \\
\hline Information technology & 2 & 3 & - & - & - & 5 \\
\hline Innovation & - & - & 6 & - & 4 & 10 \\
\hline Intuition & - & 1 & - & 3 & 4 & 8 \\
\hline Knowledge management & 1 & - & 3 & 5 & - & 9 \\
\hline Leadership & 1 & - & - & 3 & - & 4 \\
\hline Learning & 3 & - & - & 4 & - & 7 \\
\hline Management & 1 & 2 & - & - & - & 3 \\
\hline Management accounting & - & - & - & - & 3 & 3 \\
\hline
\end{tabular}


Table 4: (continued)

\begin{tabular}{lrrrrrr}
\hline Keywords & $1995-$ & $2000-$ & $2005-$ & $2010-$ & $2015-$ & Total \\
& 1999 & 2004 & 2009 & 2014 & 2018 & \\
\hline Managerial cognition & 1 & - & - & - & 2 & 3 \\
Managerial discretion & 2 & - & - & - & - & 2 \\
Management strategy & - & - & 3 & - & - & 3 \\
Manufacturing strategy & - & - & 2 & - & - & 2 \\
Modelling & 1 & - & 2 & - & - & 3 \\
Organizational change & 1 & - & - & - & - & 1 \\
Organizational culture & 2 & - & - & - & - & 2 \\
Organizational performance & - & - & 5 & - & - & 5 \\
Product management & 2 & - & - & - & - & 2 \\
Quality functional deployment & - & - & 2 & - & - & 2 \\
Real options & - & - & 2 & - & - & 2 \\
Performance & - & - & 6 & 4 & 6 & 16 \\
Personality & - & - & - & 3 & - & 3 \\
Rationality & - & 1 & - & - & 3 & 4 \\
Scenario planning & - & 3 & - & - & - & 3 \\
Simulation & 2 & - & - & - & - & 2 \\
Small to medium-sized & - & - & - & 3 & - & 3 \\
Social networks & - & - & 3 & - & - & 3 \\
Stakeholders & 2 & - & - & - & - & 2 \\
Strategic change & - & 2 & - & - & - & 2 \\
Strategic decision-making & 18 & 24 & 33 & 47 & 41 & 163 \\
Strategic decisions & - & 2 & 2 & 7 & 6 & 17 \\
Strategic management & 5 & 7 & 13 & 8 & 3 & 36 \\
Strategic planning & 5 & 9 & 10 & - & 5 & 29 \\
Strategy & 11 & 7 & 6 & 16 & 4 & 44 \\
Subsidiaries & - & - & 3 & 2 & - & 5 \\
Supply chain management & - & 2 & 2 & 2 & 2 & 8 \\
Sustainability & - & - & - & 3 & 3 & 6 \\
System dynamics & - & - & - & - & 2 & 2 \\
Teams & 1 & - & - & 3 & - & 4 \\
Teamwork & 2 & - & - & - & - & 2 \\
Top management team & - & - & - & 3 & 3 & 6 \\
Uncertainty & - & 2 & - & - & - & 2 \\
United States of America & - & - & 3 & - & - & 3 \\
Upper echelons & - & - & - & - & 4 & 4 \\
\hline Total & 55 & 59 & 100 & 101 & 88 & 403 \\
\hline & & & & & &
\end{tabular}


additional key words were: 'innovation', (10 occurrences), 'decision support systems' (9 occurrences), 'knowledge management' (9 occurrences), 'supply chain management' (8 occurrences), 'learning' (7 occurrences), 'corporate strategy' (6 occurrences), 'sustainability' (6 occurrences), and 'top management team' (6 occurrences). The less commonly used keywords were: 'consensus' (1 occurrence), 'culture' (1 occurrence), 'entrepreneurship' (1 occurrence), and 'executive information' (1 occurrence). It appears that the decision process involved in strategic decision making was given less attention. Further to the above, keywords such as intuition (8 occurrences), rationality (4 occurrences), and cognition (3 occurrences) were also paid less attention in the context of decision-making. A few more keywords which reflected geographical information were also noted: India (5 occurrences), China (4 occurrences), and Australia (1 occurrence).

\subsection{Bibliometric Methods}

The bibliometric method is an important science mapping technique used in the field of bibliometrics (Cobo, López-Herrera, Herrera-Viedma, \& Herrera, 2011, 2012; van Eck \& Waltman, 2009). It is commonly used to measure the influence and the similarity of citation analysis, cocitation analysis, author analysis, co-author analysis, and bibliographical coupling (Zupic \& Čater, 2015). Our study also utilised complementary bibliometric tools for constructing the intellectual structure and the evolution of strategic decision. They include: (1) multidimensional data analysis using the Sankey Diagram; (2) visual network and heat map analysis using VOSviewer; (3) strategic diagram and evolution map using SciMAT.

In the past few years, Sankey Diagrams have been applied in various ways to perform the multi-dimensional analysis that illustrates the flow of energy. It was first used on steam engines, but in recent years, Sankey Diagrams have also been used on modern energy generating systems including power plants and global energy (Lupton \& Allwood, 2017; Soundararajan, Ho, \& Su, 2014; Subramanyam, Paramshivan, Kumar, \& Mondal, 2015). Our study also applied the Sankey Diagram (https://medialab.sciencespo.fr/) to analyse the given datasets, and to visualise the flow of authorship, scientific themes, and journals based on a yearly basis. The Sankey Diagram is becoming particularly relevant for longitudinal analysis, especially when datasets are more detailed 
(Lupton \& Allwood, 2017). While the analysis highlights the statistics, the visualisation analyses the inter-linkages and the inter-dependencies of the various studies with regards to SD research (Soundararajan et al., 2014). From the datasets gathered, a scientific mapping based on key trends was then conducted for each year from 1971 to 2018. These processes were visualised and interactively explored. To the best of our knowledge, our study appears to be the first attempt to perform a multidimensional analysis and the visualisation of SD research in the field of business and management.

Since the VOSviewer is considered a free access programme which was developed for the purpose of constructing a bibliometric map that is based on network data (van Eck \& Waltman, 2009), it was also applied in this study. This powerful bibliometric tool collects the data and builds maps for constructing and visualising the citation analysis, co-citation analysis, authorship analysis, co-authorship analysis, co-occurrences of author keywords, and bibliographic coupling (Merigó et al., 2018; van Eck \& Waltman, 2009). The citation analysis was then used to assess how the documents cited each other. This was performed by counting the number of times that A cites B, and vice versa (Merigó et al., 2018). The main advantage of this bibliometric tool over other bibliometric programmes is its emphasis on the graphical representations of the maps (Castillo-Vergara, Alvarez-Marin, \& Placencio-Hidalgo, 2018).

At the same time, the co-citation analysis estimates the citation of each document from a similar third source; the co-authorship counts the documents which were co-authored by more than one author, and the co-occurrence analysis then identifies the most frequent keywords used. On these maps, terms that coexist are often placed close to each other. Besides identifying the scientific terms used, our results are further classified into four clusters (Figure 2). Additionally, we also used modularity-based clustering and normalising options to smooth the visualisation of these results.

The next method, the SciMAT, is an open source bibliometric tool. It helps studies to visualise the intellectual structure and the evolution of the scientific research. It thus quantifies and visualises the thematic subfields (Heradio, Perez-Morago, Fernandez-Amoros, Cabrerizo, \& Herrera-Viedma, 2016; Cobo et al., 2011, 2012). In general, the process of science mapping consists of: (1) the preliminary data processing (data reduction, de-duplication), (2) the network extraction (cooccurrence, coupling, direct linkage), (3) normalisation (association 
strength, equivalence index, Jaccard and Salton's method), and (4) scientific mapping (clustering), analysis (network, spatial, temporal) and visualisation (Cobo et al., 2011, 2012).

The processing of the preliminary data helps to detect any duplications or misspelled items. It also performs time slicing. The duplication process then performs the data and network reductions so as to refine the data, cluster the similar words (by plurals), and to look for synonyms or duplicates in words according to the highest number of documents and repetitions. Some keywords with low informational values were, however, excluded. Prior to performing the network extraction, we grouped our datasets into four periods so as to perform a longitudinal analysis: 2000-2004, 2005-2009, 2010-2014, and 2015-2018. The period settings were based on the significant number of articles distributed in each of those years, which were found to be almost comparable. Finally, we analysed the datasets based on the following:
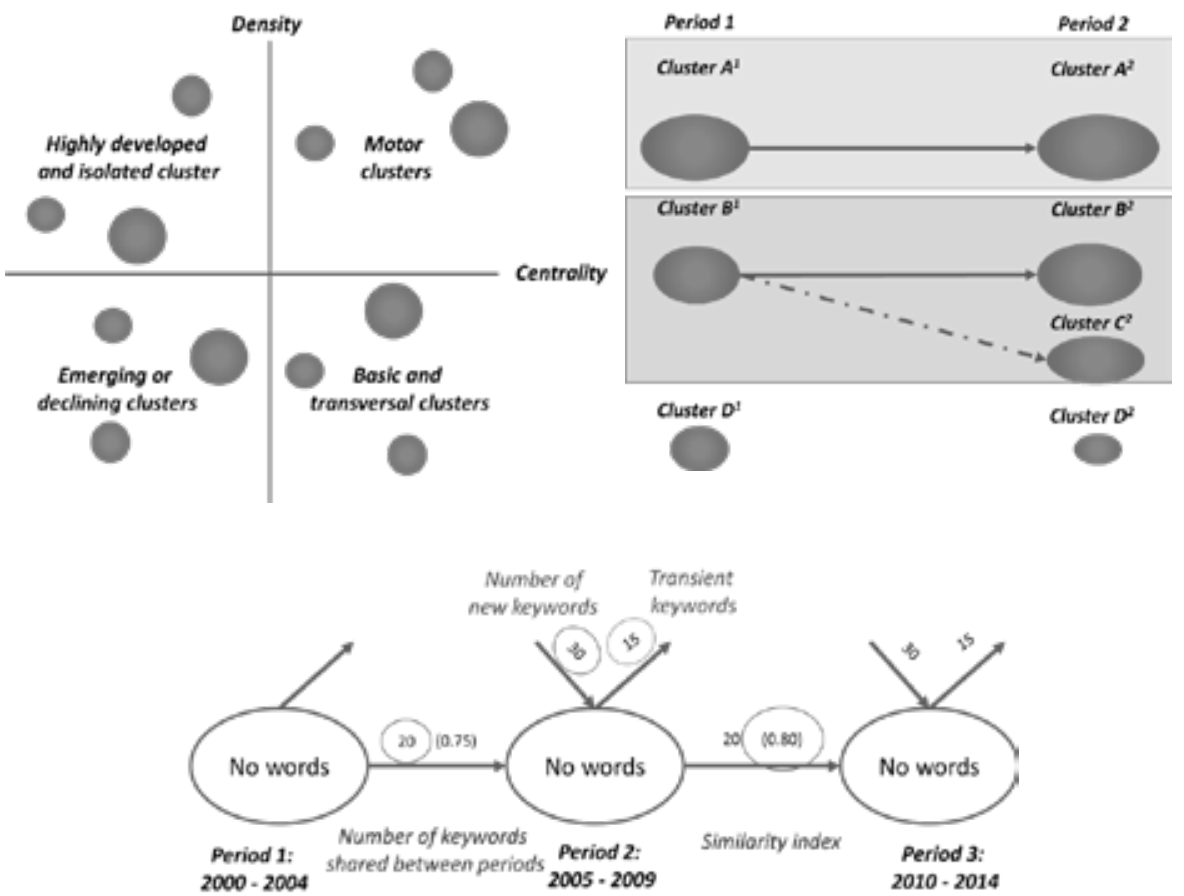

Figure 2: A Strategic Diagram of SciMAT, Evolution Map and Overlapping Graph 
the four periods and the author's words, followed by a minimum frequency for data reduction of 1 . The performance measures used for the period themes include the number of documents, the citations achieved by those documents, and h-index.

To reduce the network, we further selected the similarity measures for normalisation. Prior to the analysis, we used the equivalence index and visual mapping to identify the research themes. We projected this via the thematic networks and the strategic diagrams. We then used the longitudinal analysis to develop the evolution maps and the overlapping graphs. The configurations used include a network reduction of 1, association strength, normalisation measures, simple centre algorithms, core mapper for the document mappers, h-index and sum citations. The scientific evolution analysis we projected shows the association strength and the overlapping graph mapping thematic clusters for the particular period of time.

In the last stage of our study, we visualised the results by placing them into strategic diagrams, cluster networks, and evolutionary paths of scientific themes. The strategic diagrams highlight the identified clusters and the scientific themes for each of those four periods. This is depicted in a two-dimensional space: density and centrality (Cobo et al., 2011, 2012). The centrality measures the degree of the network interaction which represents the importance of a theme in the development of the research, but the density counts the degree of internal strength of the network. Figure 2 illustrates.

The evolution map is commonly used to identify the scientific clusters. As noted in Figure 2, the multi-sided clusters (D1 and D2) describe the evolution between the periods. The solid lines indicate that the linked clusters share the main items (commonly, the most significant one) and the dotted line describes the elements which are relatively far from the main ones. The thickness of the edges relies on the Inclusion Index which reflects the proportion of the number of published documents in each cluster (Alcaide-Muñoz, Rodríguez-Bolívar, Cobo, \& Herrera-Viedma, 2017). The evolution analysis is explained by an overlapping graph as shown in Figure 2 where the horizontal arrow explains the number of items shared by both periods. The emerging trend is depicted by an upper incoming arrow which accounts for the number of new items for period 2 and the upper outgoing arrow represents the transient items that are presented in the previous period, but not in the recent one (Alcaide-Muñoz et al., 2017). 


\section{Results and Discussion}

\subsection{Sankey Diagram}

The Sankey Diagram portrays multidimensional elements of the authors (left side), key scientific themes (middle side), and cited journals (right side). The results visualise the inter-linkages and the inter-dependencies of SD in the field of business and management from 1995 to 2018. The primary keywords often used in the first element are: 'decision-making', 'strategic decision-making', and 'strategy'. This is consistent with the keywords we applied at the initial stage of searching for the published articles in the field of SD research. The findings also highlight the major evolving trends given in the second element: learning (1995 and 2012), information technology (2001), strategic planning (2002), corporate strategy (2004), performance (2007), upper echelon (2016), and intuition (2017).

Table 3 describes a number of interdependencies among the given scientific terms. The most prolific authorship found in the third element include: Elbanna, Parayitam, Cray, Dooley and Amason. The top five co-wording terms are relatively dominated by several contexts: decision making, strategic decision making, strategy, strategic decisionmaking, and strategic management. The most influential publishers are Management Decision, Strategic Management Journal, Long Range Planning, Journal of Business Research and Decision Support System.

The findings derived are consistent with our objective which aims to examine the evolution of decision-making in business and management settings. The Sankey Diagram used illustrate some kind of interdependency among authorships, contexts, and the publishing journals. The most intensive interdependency among these three elements was Elbanna and Parayitam, as noted in the co-wording analysis of decision making published in the Management Decision journal. Our results further show that more authors contributed to the Strategic Management Journal and the Decision Science journal. Our results are in line with our preliminary analysis, thereby demonstrating the domination of the Strategic Management Journal in SD research.

Figure 3 highlights the results derived from examining cowordings. As mentioned earlier, the network analysis was classified into four clusters between 1971 and 2018. The results visualised in VOSviewer (Figure 4) reveal that the first cluster comprised: 'decision making', 'strategic planning', and 'strategic decisions'. The second cluster comprised strategic decision-making processes which depicted 


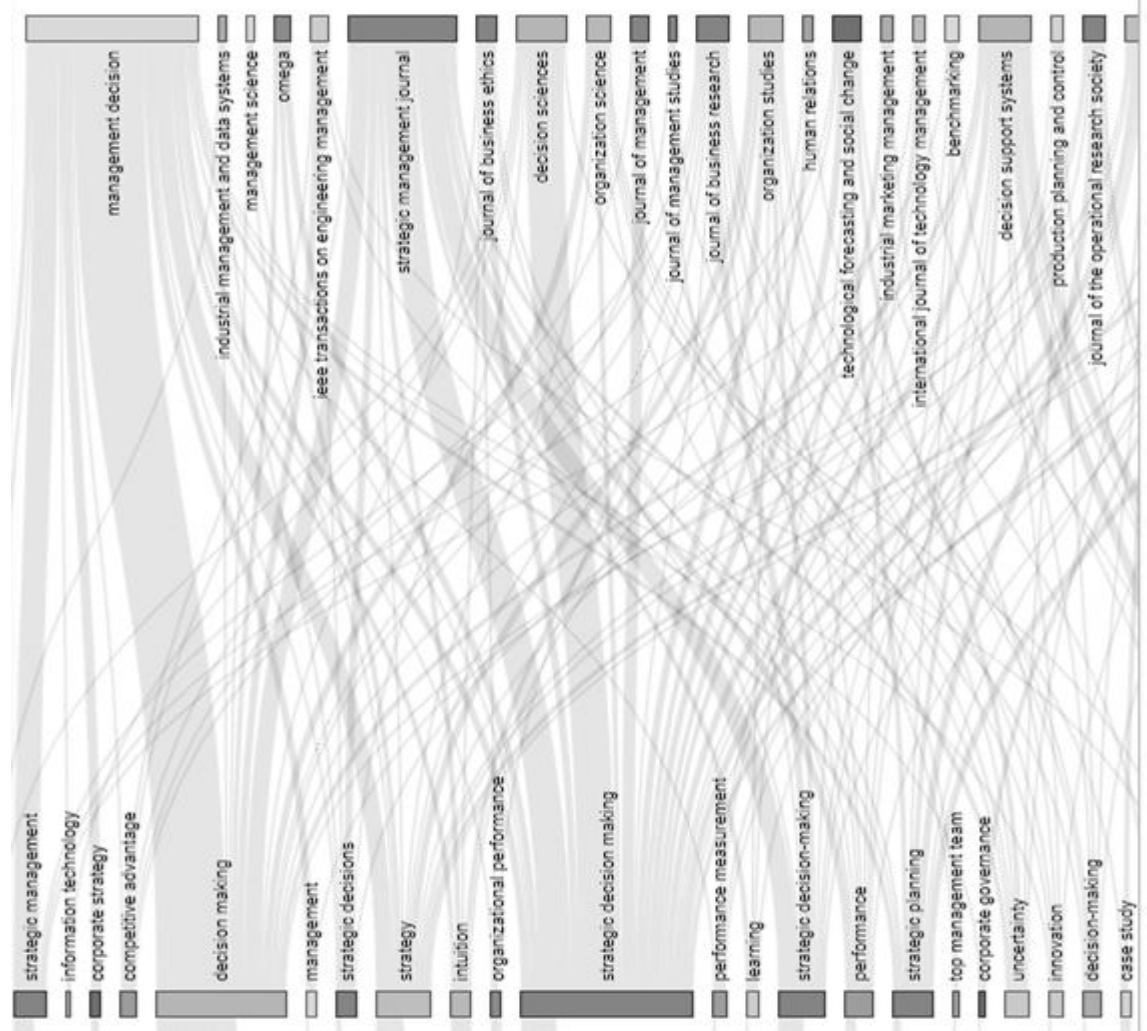

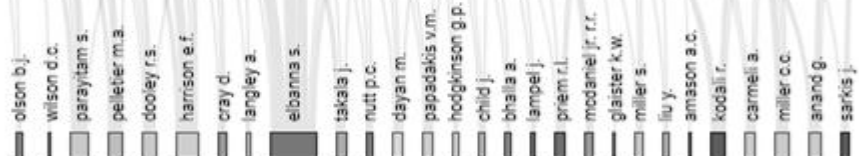




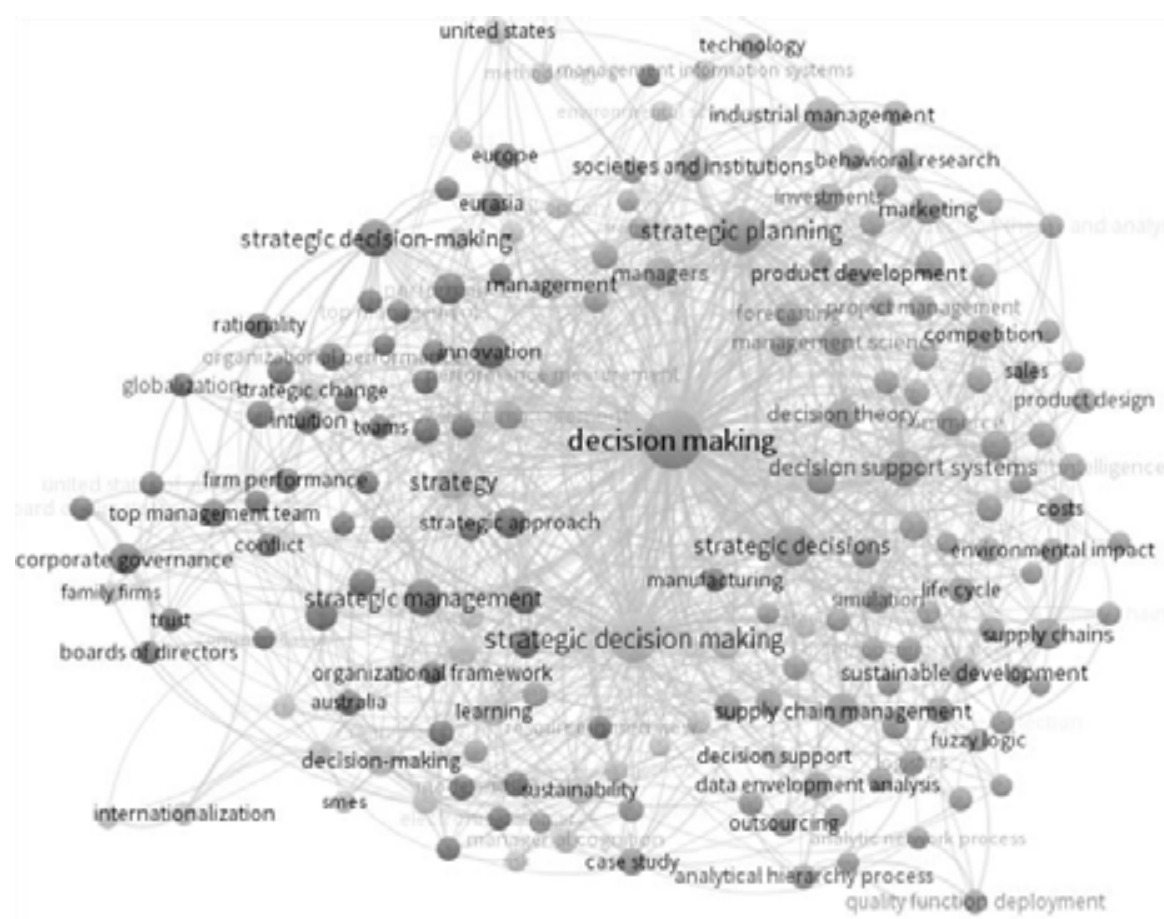

Figure 4: Mapping of the Journals' Bibliographic Coupling during 1971 and 2018

'rationality', and 'intuition'. The third cluster describing the decision tools comprised 'a decision support system', and 'fuzzy logic' while the last cluster comprised SD research involving 'strategic decision making', and 'strategy'.

The Sankey diagram in Figure 3 highlights the published articles according to authors and keywords used while Table 5 highlights the hard evidence indicating the various authors who had contributed to the respective journals, the number of publications derived, the keywords used, and the name of the main journals. The table also highlights the trends that persisted during the same period.

\subsection{The Cluster Analysis of Decision-Making}

\subsubsection{The Evolutionary Trends of Decision-Making (1971-2018)}

The trends for decision-making for the four periods of analysis in our study had generated several outcomes which are further depicted in Figure 4. 


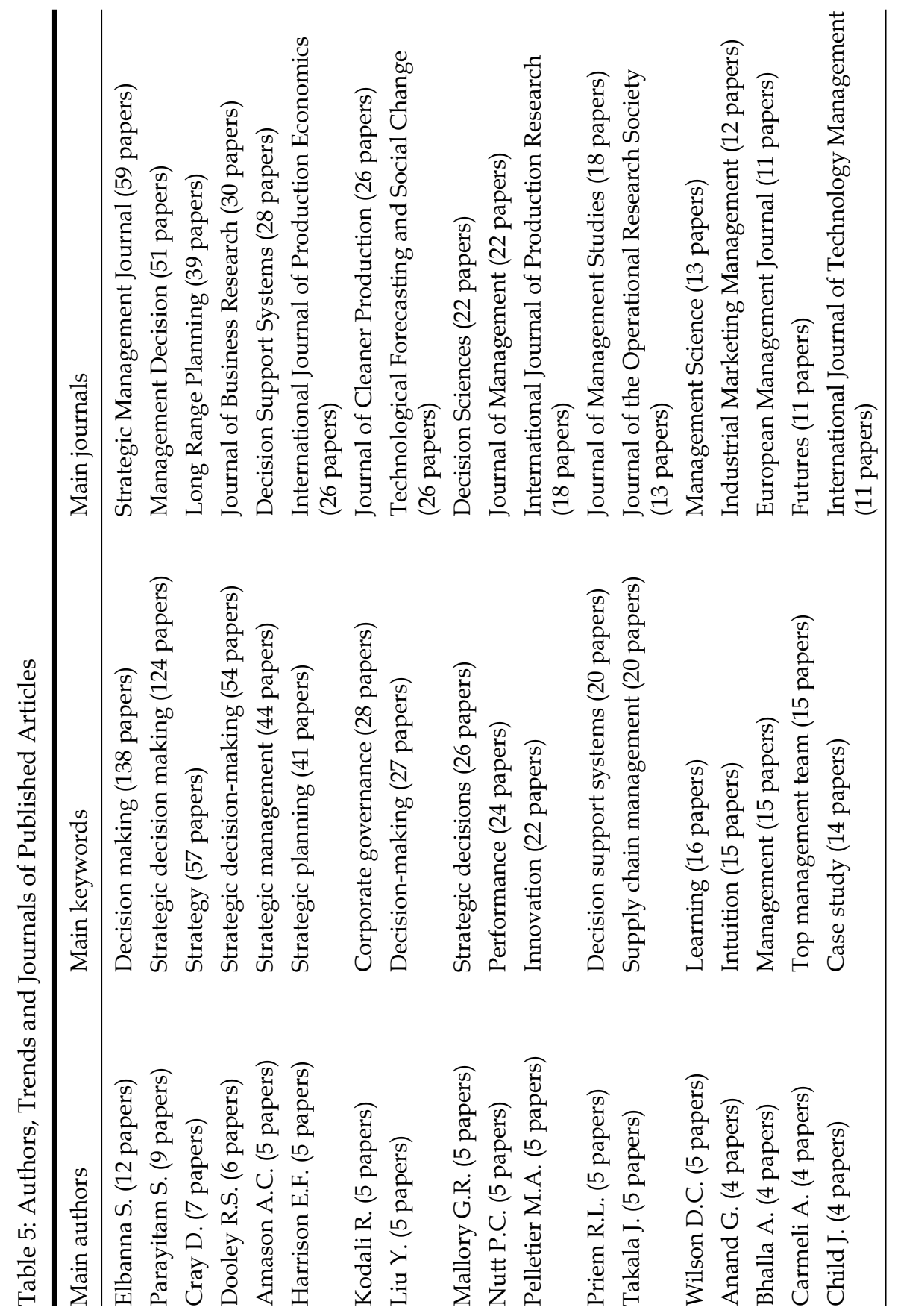


Harry Patria, Sari Wahyuni and Ratih Dyah Kusumastuti

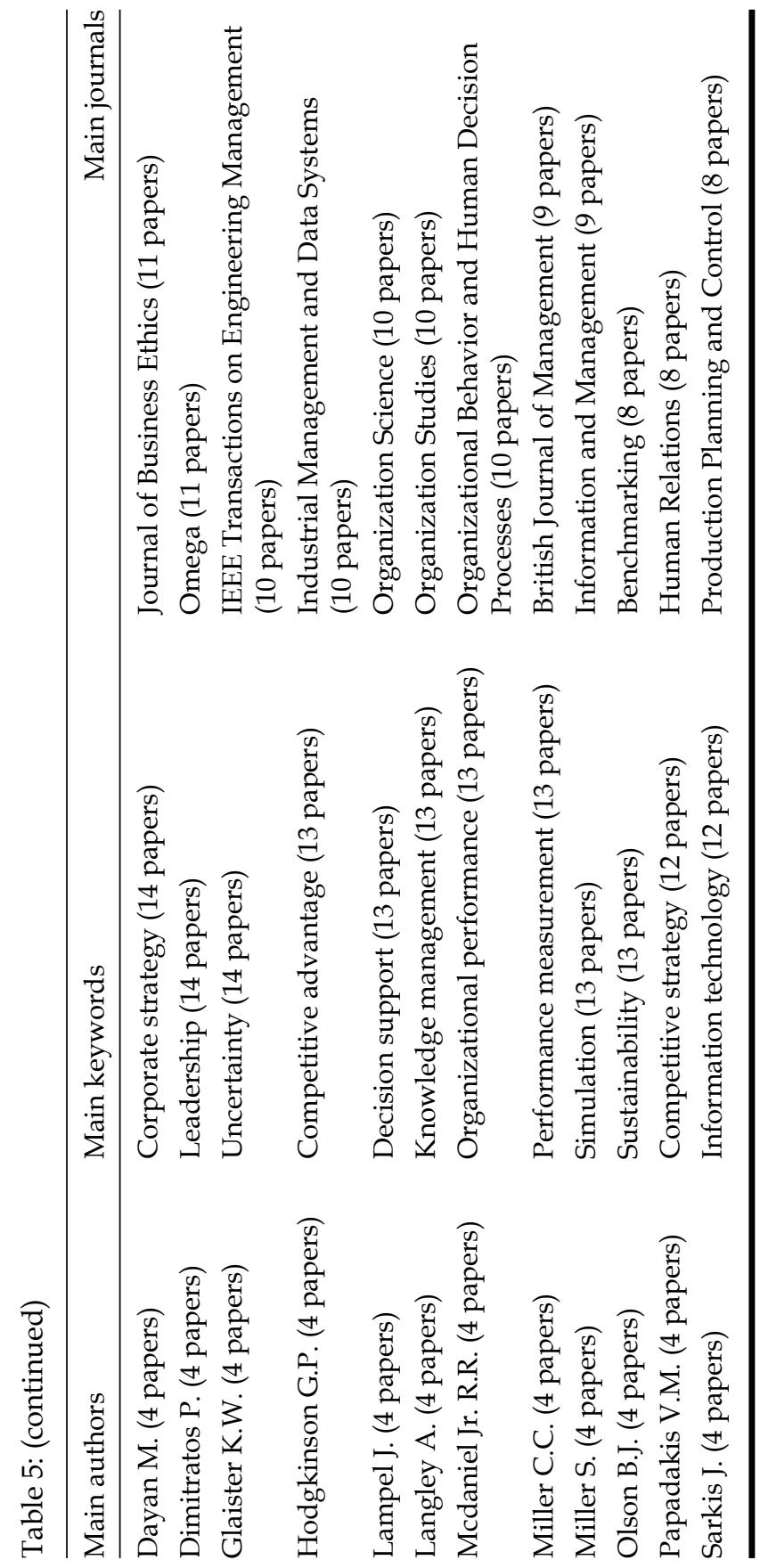


Based on Figure 4, it can be seen that the SD processes had evolved in diverse ways over 48 years, from 1971 to 2018. As time progressively advanced, the key words of 'analytical hierarchy process', 'fuzzy logic', 'decision support system', 'rationality', 'intuition' and 'political decision' also became a part of behavioural research, data analytics, and artificial intelligence. The clusters revealed that SD research had been conducted in diverse fields of business and management such as: 'strategic planning', 'supply chain management', 'manufacturing', 'product development', 'investment', 'marketing', and 'industrial management'. Our findings of the four periods are subsequently discussed below.

\subsubsection{The Emergence of Decision-Making during Periods of 1971-1989 and} 1990-1999

Figure 5 below illustrates the results derived from the four clusters. The first cluster contained terms including 'strategic decision', 'decision support system', and 'decision theory'. The second cluster is comprised of terms including 'decision making', and 'information'. The third and fourth clusters, which are described as the minor trends of decision

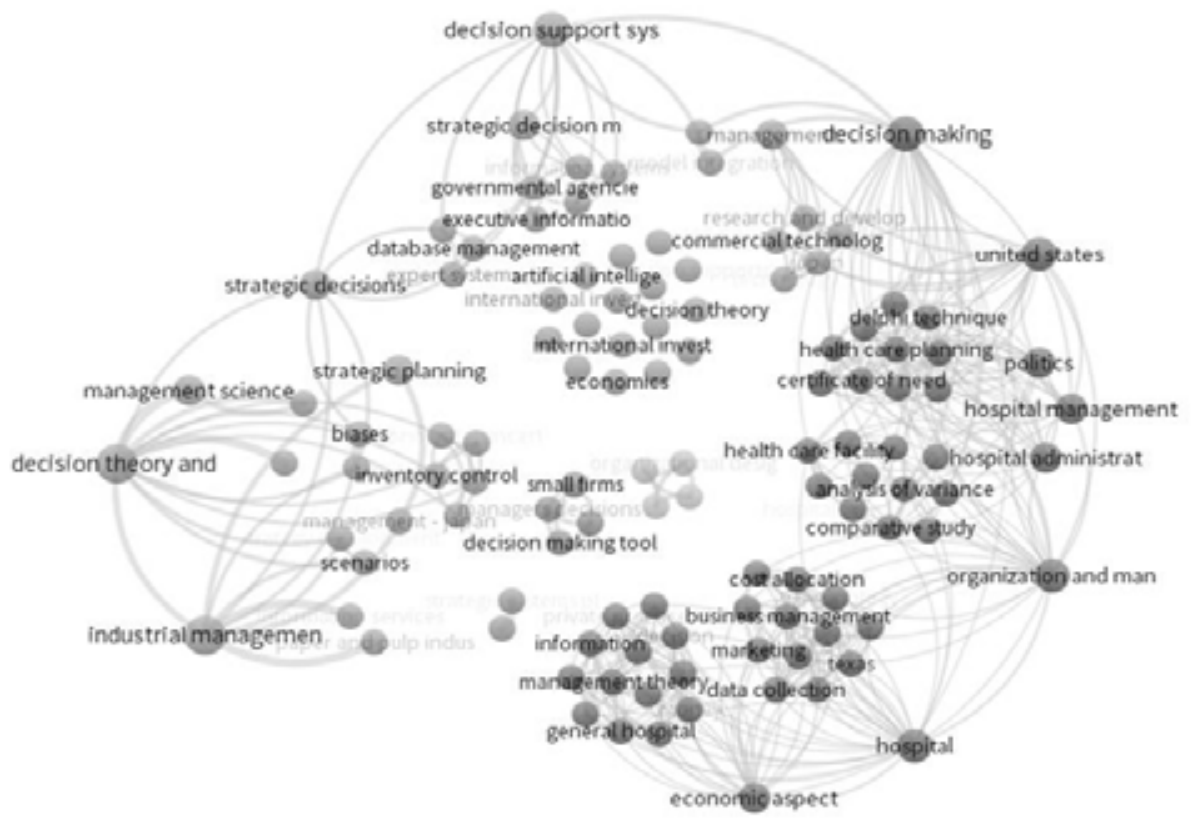

Figure 5: Mapping of Journals Bibliographic Coupling during 1971 and 1989 
making contains terms such as 'decision-making tools' and 'managers' decision'. Although only a few published articles were available during this period, the trends, nonetheless, indicated the emergence of strategic decision-making. As can be noticed, decision-making had evolved in diverse contexts such as 'industrial management', 'international investment', 'economy', 'inventory control', 'business', and 'hospital management'.

Figure 6 illustrates the analysis derived from our examination of the articles for the time period of 1990 to 1999. Here, it was noted that SD literature had advanced into diverse emerging trends such as: (i) 'product management' and 'artificial intelligence'; (ii) 'knowledge' and 'expert system', and (iii) 'group support system' and 'politics'. This period of time also visualised four clusters and their interdependencies. The first cluster comprises of 'decision-making', 'strategic planning', and 'product management' while the second cluster contains 'strategy', 'management', and 'leadership'. The third cluster visualised other cowordings such as 'strategic decision-making', 'group support system', 'managerial cognition', and 'politics'. The subsequent cluster depicted other emerging trends of decision making such as 'expert systems' and 'knowledge representation'.

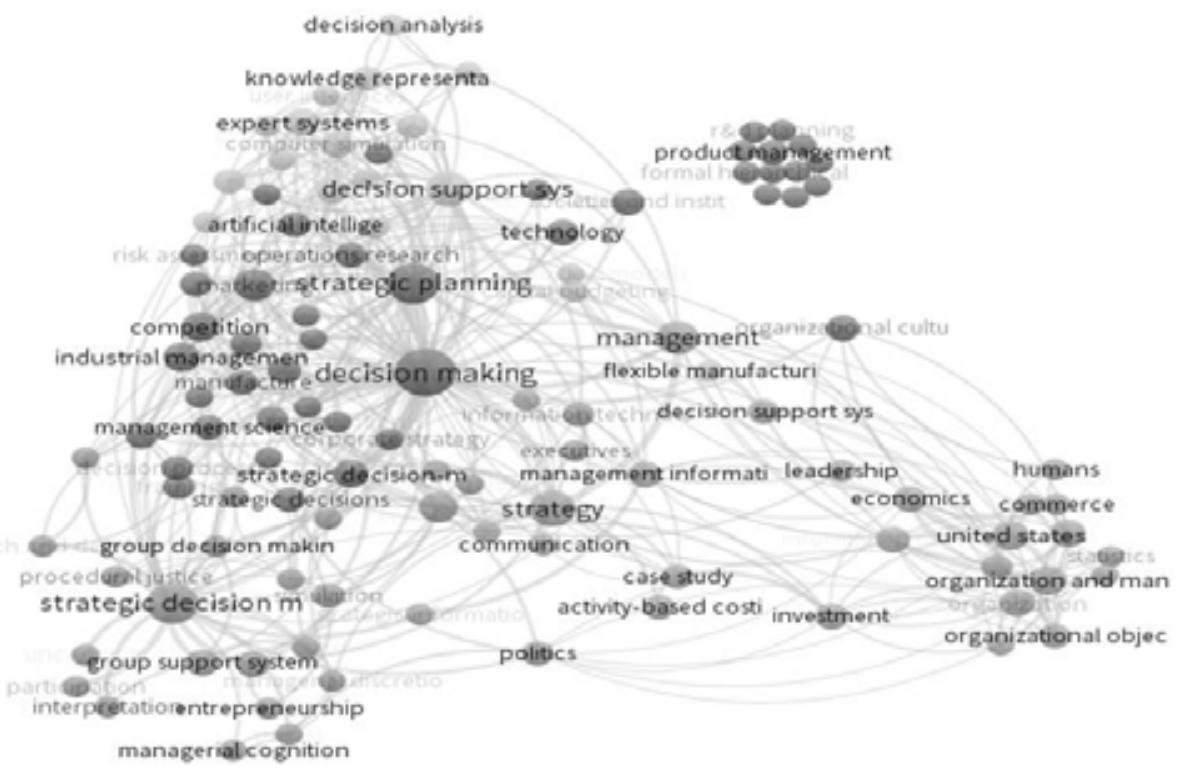

Figure 6: Mapping of Journals Bibliographic Coupling during 1990 and 1999 


\subsubsection{The Emergence of Strategic Decisions (2000-2004 and 2005-2009)}

Since a substantial number of articles were located during this period of time, we balanced the number of articles by shortening the time period to 5 years, i.e., 2000-2004, and 2005-2009. They represent the third and fourth time period. Figure 7 illustrates results drawn for 2000 to 2004 while Figure 8 illustrates results obtained for 2005 to 2009.

\subsubsection{The Latest Development and Evolution of Decision-Making (2010-2018)}

This section illustrates the sub-major themes and their interdependencies in the final and latest stage of the time period from 2010 to 2018. Figure 9 illustrates results drawn for 2010 to 2014 while Figure 10 illustrates results obtained for 2015 to 2018. In the figures provided, the first cluster comprised of keywords which include: 'strategic decision', 'decision support system', and 'decision theory' while the second cluster portrayed keywords such as: 'decision making' and 'information'. The rest of the clusters portrayed other minor trends of decision making such as 'decision-making tools' and 'managers' decision'.

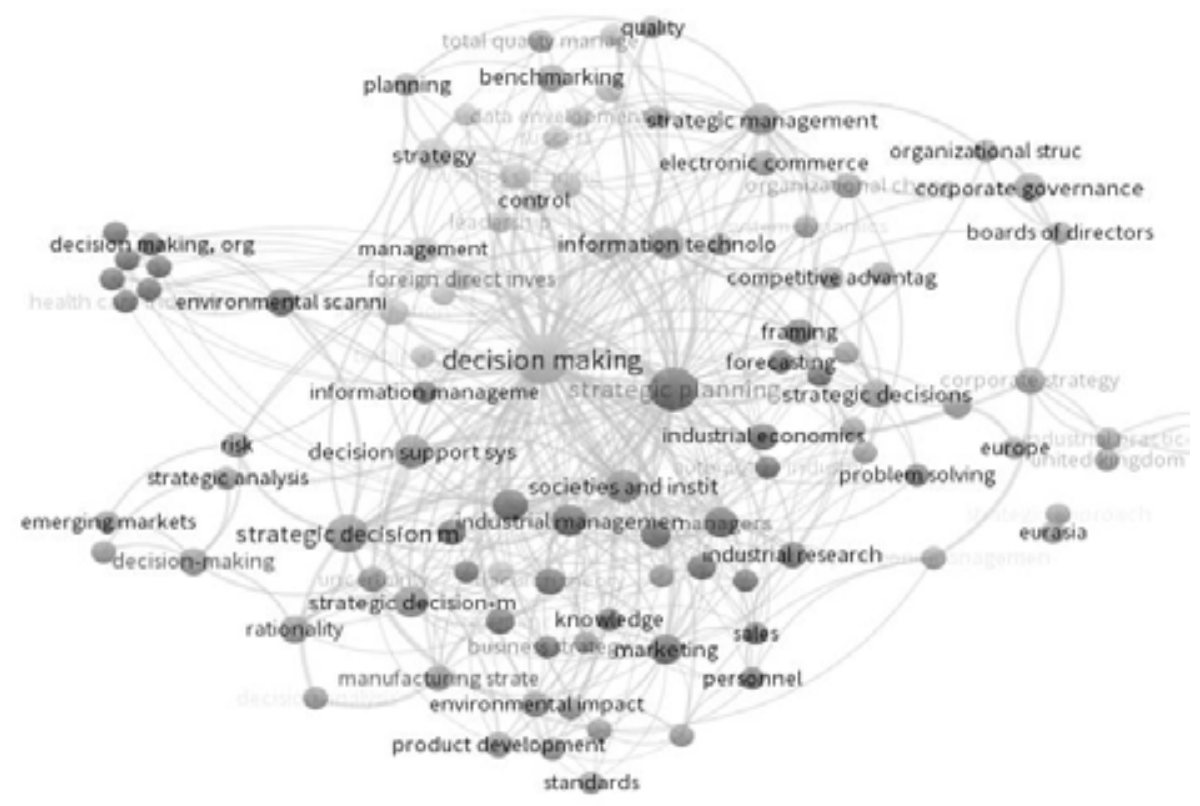

Figure 7: Mapping of Journals Bibliographic Coupling during 2000 and 2004 


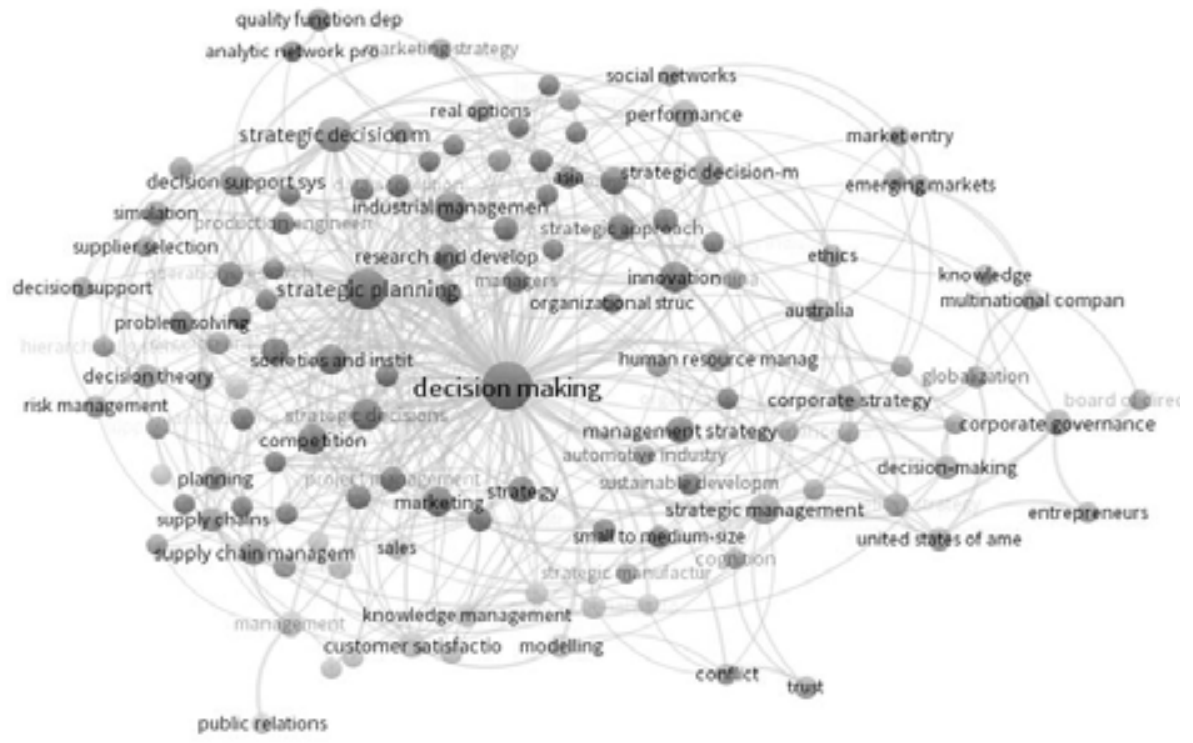

Figure 8: Mapping of Journals Bibliographic Coupling during 2005 and 2009

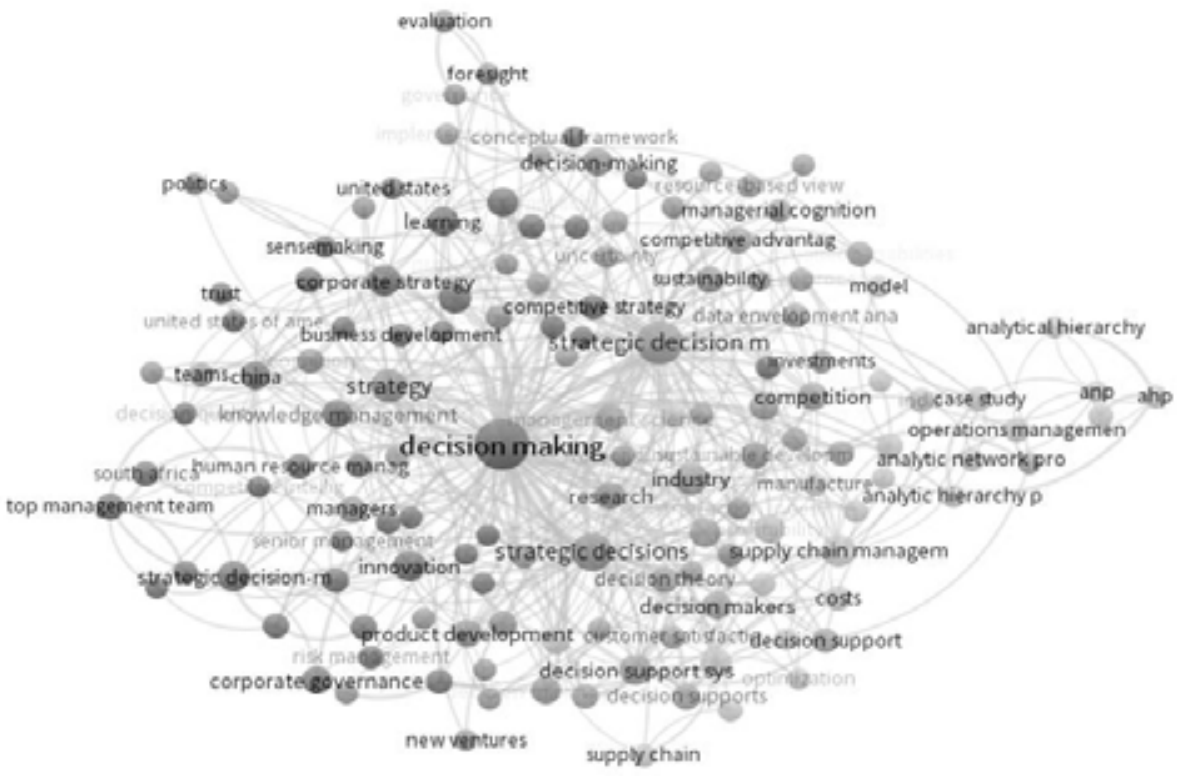

Figure 9: Mapping of Journals Bibliographic Coupling during 2010 and 2014 


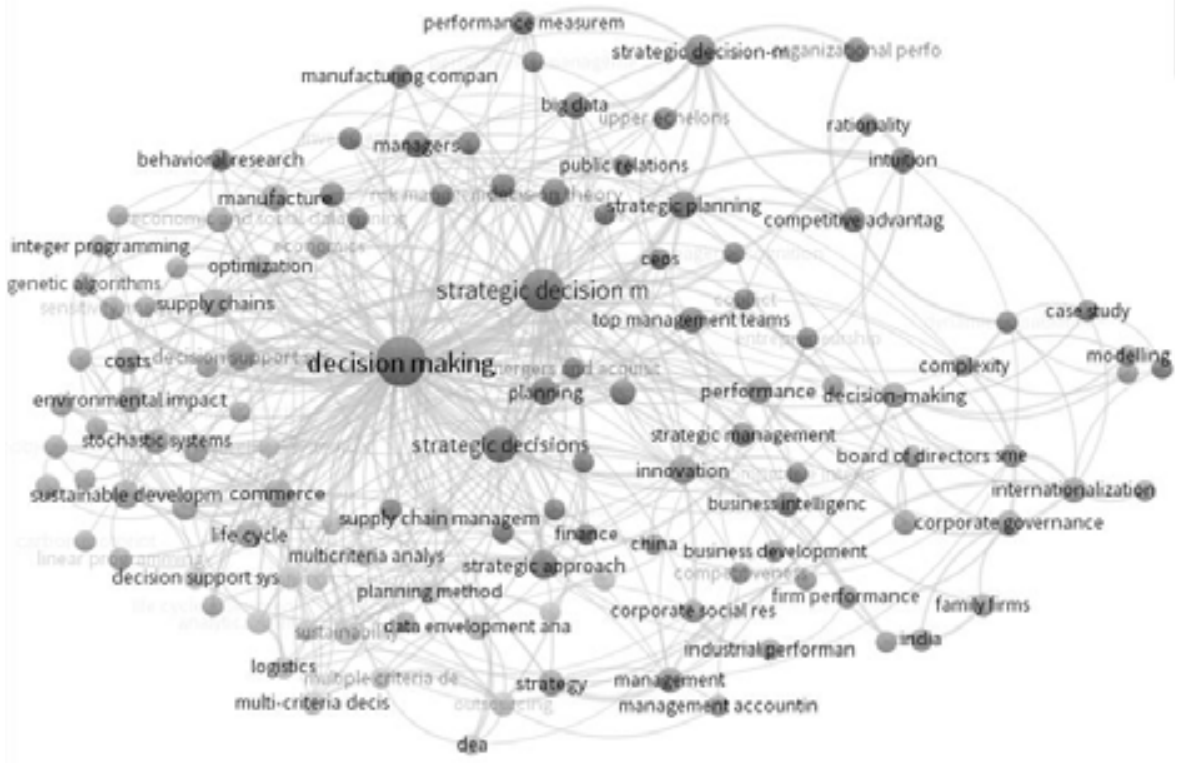

Figure 10: Mapping of Journals Bibliographic Coupling during 2015 and 2018

\subsubsection{The Bibliometric Analysis and Mapping by Authors and Country} (1971-2018)

This literature review also performed a bibliometric analysis of the authors who had published within the 48 years as noted in our study. Besides this, we also conducted a bibliometric analysis of the country of their origin so as to better understand the region that was most prolific. Figure 11 outlines the overall outcome generated from the scientific mapping while Figure 12 displays the more detailed results of the authors and their countries of origin.

To further understand the trend of the published articles, we proceeded to analysing authorships and those networks that had contributed to the decision-making field throughout the time period we had selected. Focusing on the individual researchers, based on performance analysis, the findings visualised the prolific scholars from the early period as: Eisenhardt, Papadakis, Sharfman, and Schwenk while the latest period comprised of emerging authors such as: Hodgkinson, Parayitam, and Elbanna. By far, these individuals were considered to be the most influential scholars in this field of research 

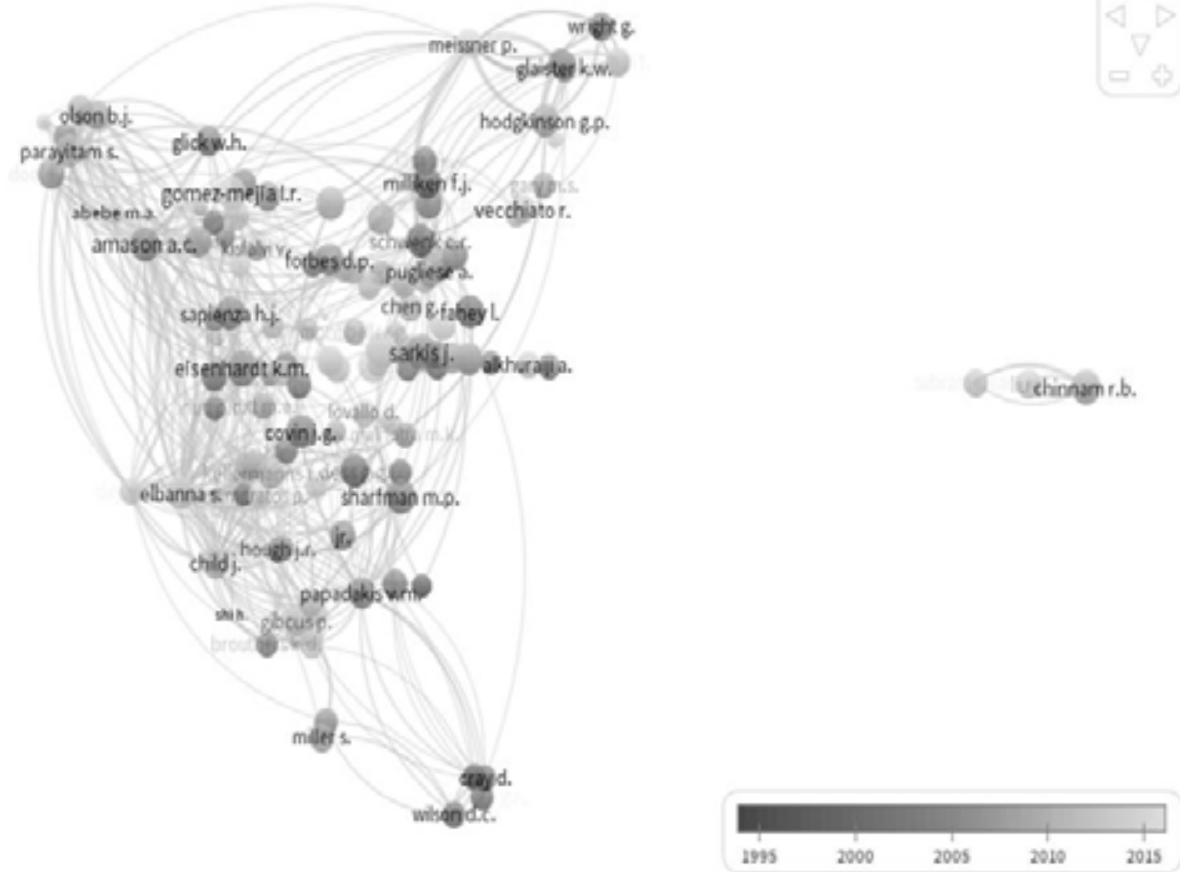

Figure 11: Longitudinal Mapping of Journals Bibliographic Coupling during 1971 and 2018

with the strongest networking found to be between Eisenhardt, Elbanna, Parayitam, Child and Papadakis.

Further to the bibliometric analysis, we also performed the bibliometric coupling by selecting the countries which were related to the scientific articles. The findings reveal that the SD literature is exclusively concentrated on developed countries such as the United States and the United Kingdom. With regards to academic institutions, it is found that both countries have the largest number of universities, hence their huge influence in the field of strategic decision-making.

Without doubt, these two developed nations are the absolute leader in this research field with the best indicator for influence and productivity in all the dimension we had analysed so far. It appears that the strongest networking for joint scientific productions is also between these two developed countries. Results further indicate that the transitioning and emerging countries have acquired second place as noted in the clusters while other countries such as Australia, Canada, 


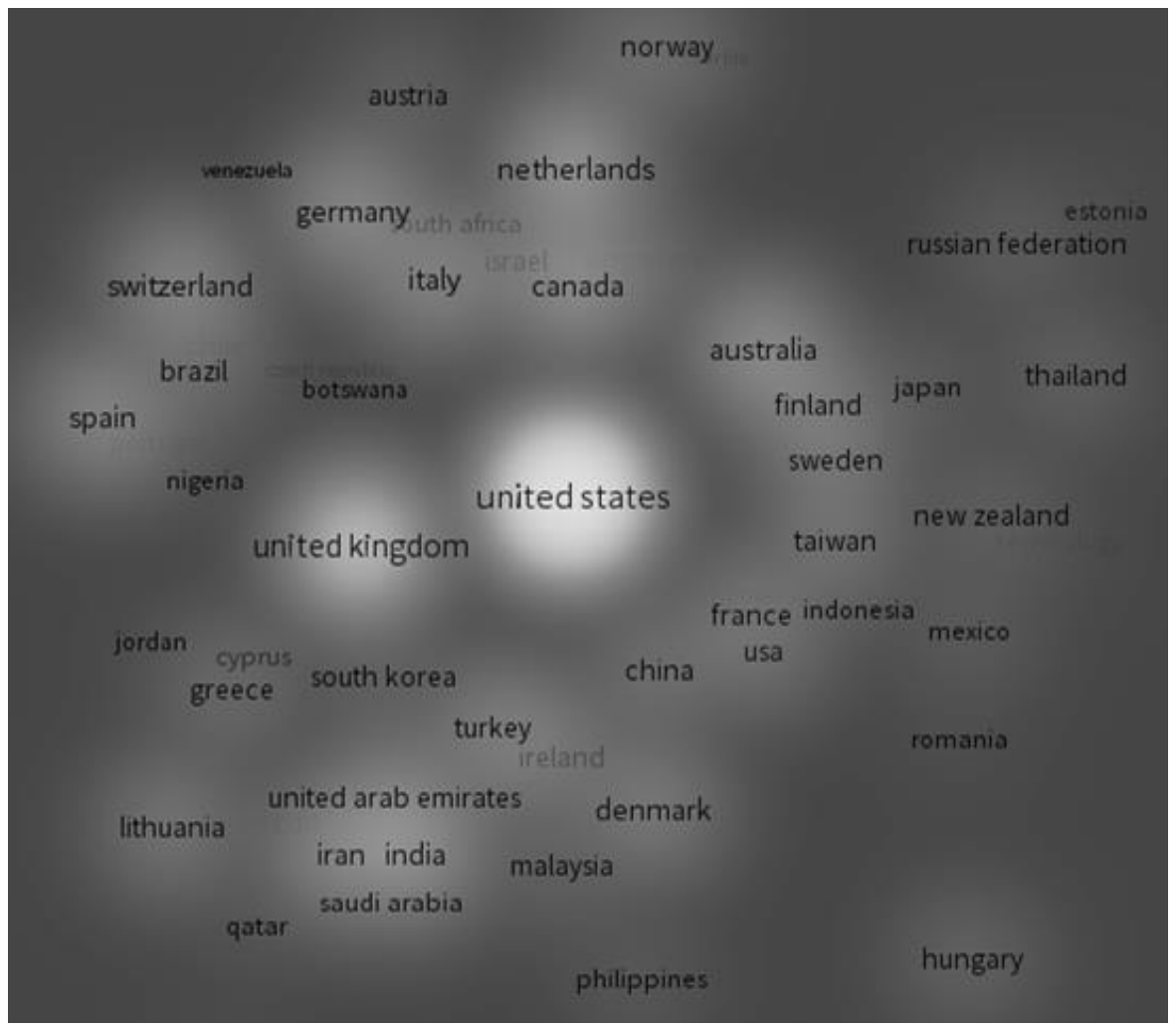

Figure 12: Mapping of Journals Bibliographic Coupling by Country during 1971 and 2018

China, Spain, Greece and the United Arab Emirates are also fairly influential, but with lesser productivity. The results explain that the geographical gaps need to be addressed in future research.

\subsection{Scientific Mapping and Evolution}

According to the evolution analysis illustrated by the SciMAT, the scientific mapping of the evolutionary trends were classified into four strategic diagrams, following the time period of 2000 to 2018. In this regard, we used a proportional number of published articles which were associated with each research theme instead of the datasets from 1971 to 1999. Co-occurrences analysis was then applied so as to map the decision-making literature with the subfields identified. This was 


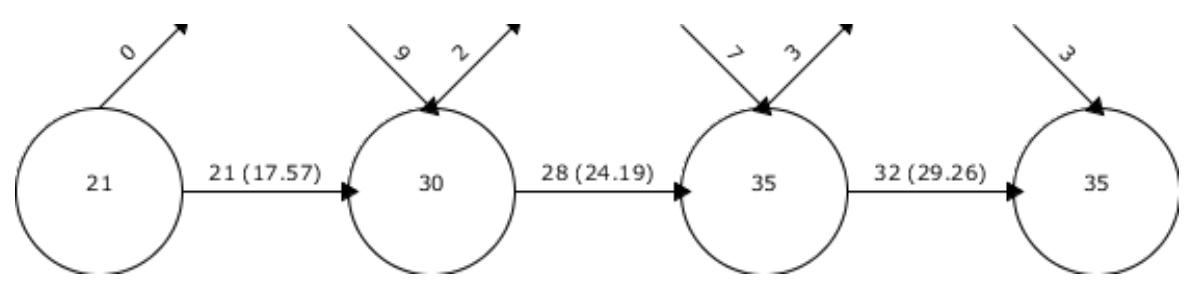

Figure 13: Overlapping Graph and Longitudinal Results of Evolution during Periods

accomplished by measuring the association strength of the publication keywords (Cobo et al., 2011, 2012; Heradio et al., 2016). Results were then automatically plotted by document count of articles based on density and centrality. This is illustrated in Figure 13.

Figure 13 highlights the overlapping graph which represents the number of items shared within the periods of: (i) 2000-2004, (ii) 20052009, (iii) 2010-2014, and (iv) 2015-2018. It is observed that the number of items shared by periods had increased from 21 items in the first period to 35 items in the last period. This outcome reveals that the number of new and transient keywords was relatively high while the number of shared keywords between successive sub-periods had increased, thereby leading to the higher similarity indices (17.57, 24.19 and 29.26). These signs suggest that the research field had not reached a stage of maturity yet.

The upper incoming line in Figure 13 demonstrates the number of new items in a period while the upper outgoing arrow displays the items that were presented in the prior period. The results show that the number of new items is relatively higher during the second period ( 9 items) and third period (7 items). The number declined to three (3) items during the last period. This shows that the items presented in the prior period had increased from two items in the second period to three items in the last period.

With reference to the strategic diagram shown in Figure 14, the analysis shows that the research seemed to have fragmented in the major scientific themes. This is consistent with our study which focusses on the themes of: decision-making, rationality, behavioural economics, bounded rationality and intuition (high centrality-high density). The results also show some research areas using other scientific themes such as: political-decisions, leadership, entrepreneurship (low centralityhigh density), strategic planning, game theory and real options (high 


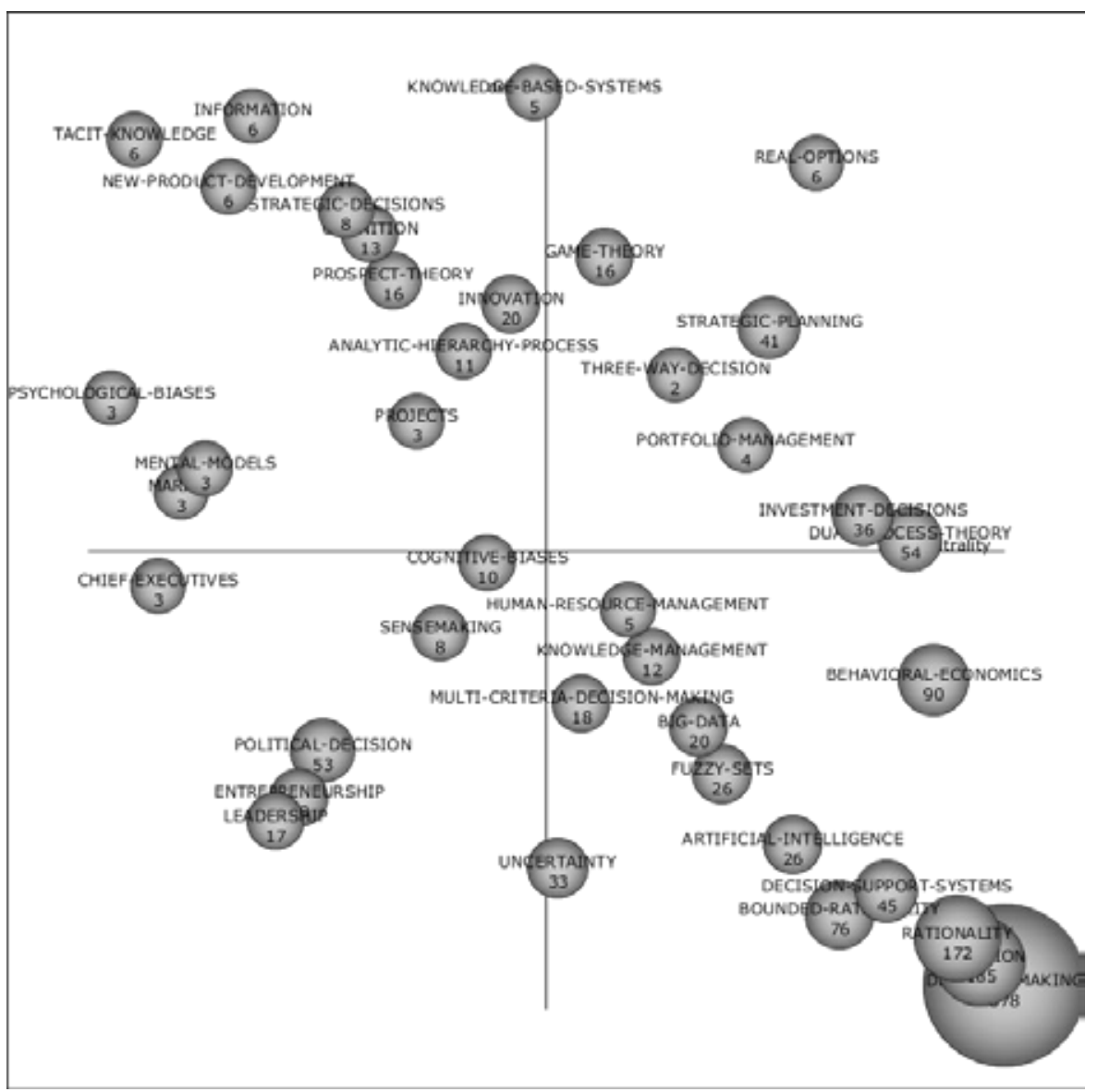

Figure 14: Strategic Map Diagram Using SciMAT 1971-2018 (document counts)

centrality-low density), and innovation and prospect theory (low centrality-low density). According to the strategic map diagram, the decision-making field had concentrated on several major themes throughout the whole time period. The first cluster discloses the motor themes (quadrant 1) such as: real option, strategic planning, game theory, investment decision, dual process theory, three-way-decision and portfolio management. These scientific themes were well developed and crucial for the structuring of decision-making. These research topics that are associated with decision-making are central to the contextual cases of strategic planning, portfolio management, and investment 
decisions. It appears that the new approach paved by the dual process theory, three-way-decision, and game theory have transformed the way decisions were made during those time periods.

In the same figure, the second cluster highlights the highly developed but isolated topics (quadrant 2) of: innovation, prospect theory, cognition, analytic hierarchy process, strategic decisions, new product development, information, tacit knowledge, projects, psychological bias, mental models and market. These research topics are associated with how strategic decision making served as a central element for issues related to innovation, prospect theory, cognition and analytic hierarchy process. The third cluster in the same figure projects topics that are marginal and inadequately developed such as emerging or disappearing topics. They include: political decision, entrepreneurship, leadership, cognitive bias, sense-making and chief of executives.

The last quadrant projects the imperative topics which are weakly structured. They encompass: decision-making, intuition, rationality, behavioural economics, bounded rationality, decision support system, uncertainty, artificial intelligence, fuzzy sets, big data, multi-criteria decision making, knowledge and human resource management. Our findings reveal that strategic decision-making has a wide perspective from classical scientific themes of synoptic and incremental perspectives (rationality, intuition, bounded rationality and decision support system) to neo-classical scientific themes (behavioural economics, artificial intelligence and big data).

According to the performance measures we applied, several major themes were detected. These include: decision-making, intuition, rationality, bounded rationality, decision support system, dual process theory, and political decision. These research themes are able to gather a significant impact rate, achieving more than 50 citations, and getting higher h-indexes when compared to the remaining themes. Our results also establish several very important themes for the decision-making research. They include: decision-making, and intuition (2000-2004), bounded rationality, and uncertainty (2005-2009), decision support system, and artificial intelligence (2010-2014), and decision-making and intuition (2015-2019).

According to the centrality and density of our results, it is observed that the most important themes for the decision-making research were: decision-making, intuition, rationality, bounded rationality, and the decision support system. It should be noted too that both themes had accomplished great impact measures (citation and h-index). Overall, our 
results also summarise the top co-wordings based on centrality from 1971-2018. They encompassed: decision-making, intuition, rationality, behavioural economics, bounded rationality and investment decision. Our results also locate the topmost themes based on centrality range. They include: decision-making, intuition, rationality, behavioural economics and decision support system. The five topmost themes that are based on density range were: knowledge-based systems, information, tacit knowledge, new product development and strategic decisions.

In this study, the impact of the co-wording terms was analysed using the average citation among the co-wording maps within each cluster by using the relational database extracted from the decisionmaking articles. The results are able to exhibit the strategic diagram of the evolution and also a set of thematic networks. Our results also reveal that the major themes are related to the decision-making field such as: analytical hierarchy process, cognitive biases, bounded rationality, real options, multi-criteria decision, cognition, knowledge-based systems, behavioural economics, strategic planning, artificial intelligence, decision support system and intuition.

Towards the end of our analysis, it is found that the most developed theme, and the one that is most important for the construction of the scientific field, is decision-making, given that it represents a strong centrality and a high density. Research on the topic of strategic decision is related to aspects involving dynamic capability where strategic decision-making is a relevant factor. This has been studied by Eisenhardt, Miller and Papadakis. In comparison, research on the topic of behavioural decision is related to aspects involving intuition. This has been conducted by Elbanna, Child and Hodgkinson. The findings from these studies are in line with our focus on decision-making, rationality, behavioural economics and intuition. Consequently, the trend in research themes development was identifiable, thereby making it more conducive for future research to explore further.

\subsubsection{The Scientific Mapping of Strategic Decision (2000-2004)}

In order to visualise the most prominent scientific themes of strategic decision-making in the field of business and management in the two sub-consecutive periods of 2000 to 2004 and 2005 to 2009, we used SciMAT to develop the strategic diagram. Figure 15 is provided.

It was observed that from 2000 to 2004 there has been a rapid rise in the study of decision-making. According to the centrality and density 


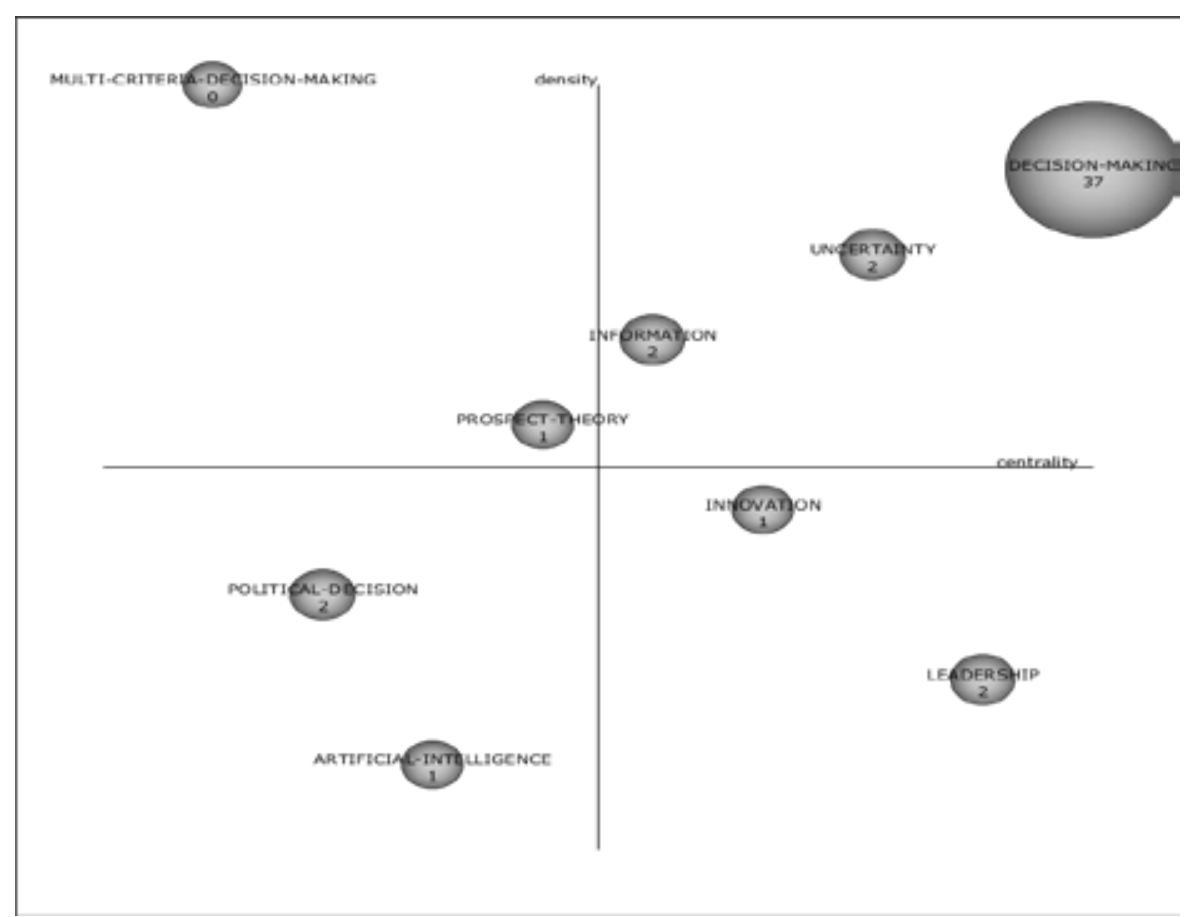

Figure 15: Strategic Map Diagram Using SciMAT 2000-2004 (secondary document counts)

of the results, the most significant of these themes were: decisionmaking, uncertainty, and information. The impact created by themes include citation and h-index which were relatively well developed, and important for a given scientific field in a given period of time. This is referred to as the motor themes, in quadrant 1 . The underdeveloped themes are shown in quadrant 2 . They are relatively important, weakly structured but possibly of considerable significance (Cobo et al., 2011, 2012; Heradio et al., 2016). These themes comprise leadership and innovation. The declining themes in quadrant 3 are inadequately developed and marginal, encompassing artificial intelligence and political decision. They are either emerging or disappearing topics. Finally, the basic themes presented in quadrant 4 are prospect theory and multi-criteria decision-making. They are well-developed internal links but they have marginal external ties.

According to the cluster network (Figure 16), the decision-making has a central role that is mainly associated with major scientific themes 


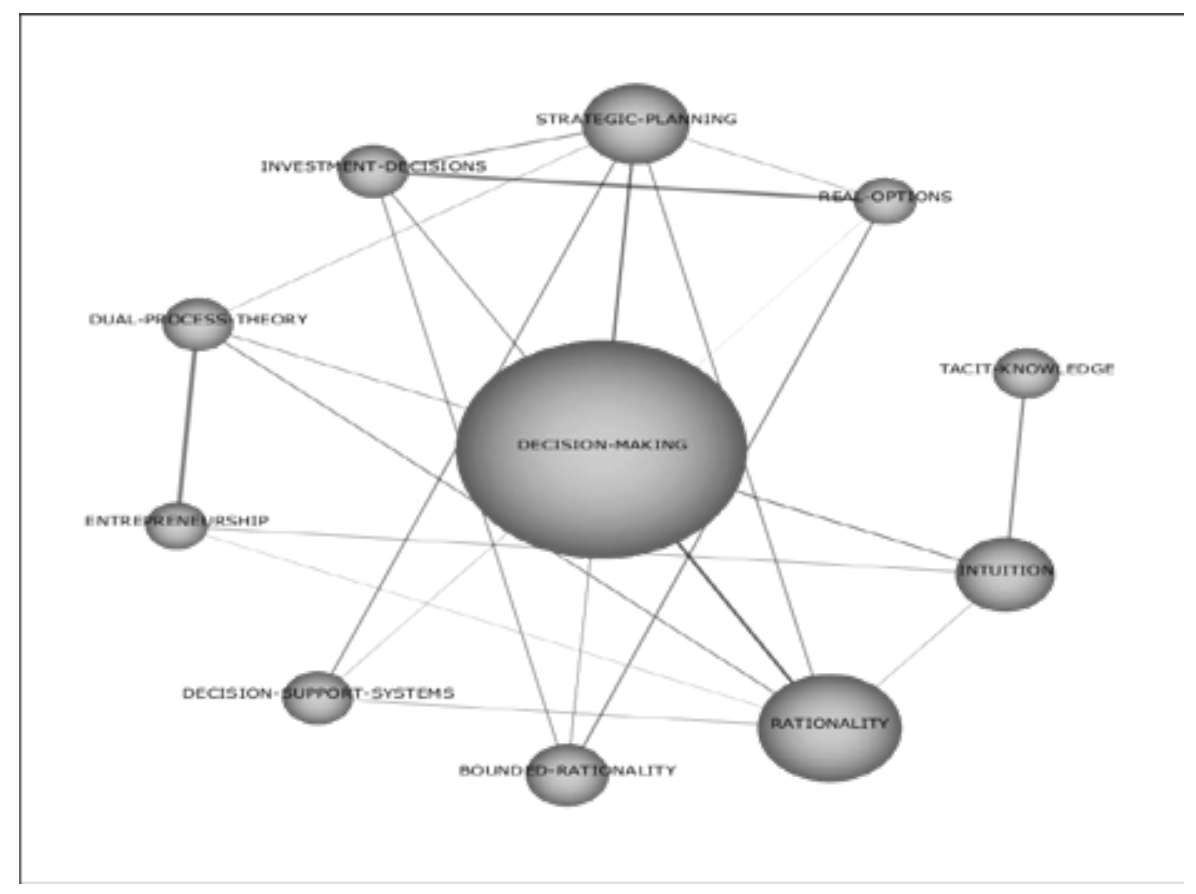

Figure 16: Cluster Network Using SciMAT 2000-2004 (decision making)

such as rationality, strategic planning, intuition, bounded rationality decision support systems. While the rest of the cluster presented the minor scientific themes such as: dual process theory, investment decision, real options, entrepreneurship and tacit knowledge, it seems obvious that decision-making plays a vital role among the scientific themes. It seems to have a powerful influence on other scientific themes as shown in the cluster network for the period of 2000 to 2004.

\subsubsection{The Scientific Mapping of Strategic Decision (2005-2009)}

Based on the strategic diagram provided by SciMAT as shown in Figure 17, it can be noticed that during the period between 2005 to 2009, the most important themes of decision-making research were: decisionmaking, bounded rationality, information and tacit knowledge. These motor themes as given in quadrant 1 of Figure 17 are relatively well developed and imperative for a given scientific field in a given period of time. The underdeveloped theme shown in quadrant 2 is strategic 


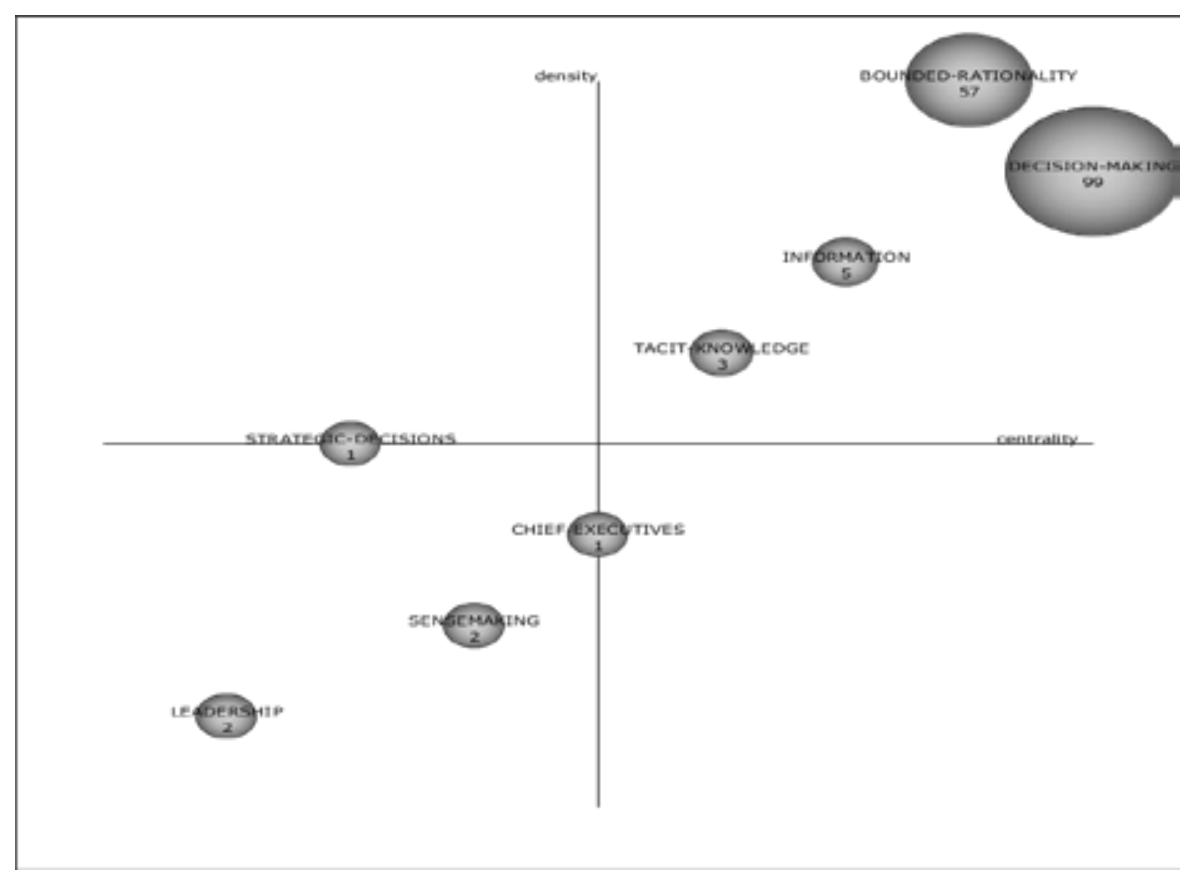

Figure 17: Strategic Map Diagram Using SciMAT 2005-2009 (secondary document counts)

decisions which is relatively important but weakly structured. This suggests that the topic of strategic decision is underdeveloped but of considerable significance for the entire research field. The declining themes presented in quadrant 3 are: leadership, and chief executives. They were inadequately developed and marginal, representing either emerging or disappearing topics. The strategic diagram has no basic and transversal themes which are commonly found in quadrant 4 .

According to the cluster network shown in Figure 18, the bounded rationality has a central role which is mainly associated with prominent scientific themes such as: uncertainty, real options, game theory, innovation and strategic planning. The rest of the cluster consists of minor scientific themes such as: political decision, dual process theory, investment decision, analytic hierarchy process, cognitive bias, behavioural economics, artificial intelligence, fuzzy sets, prospect theory, innovation and entrepreneurship. The findings reveal that bounded rationality plays a vital role in the scientific themes. It has a powerful 


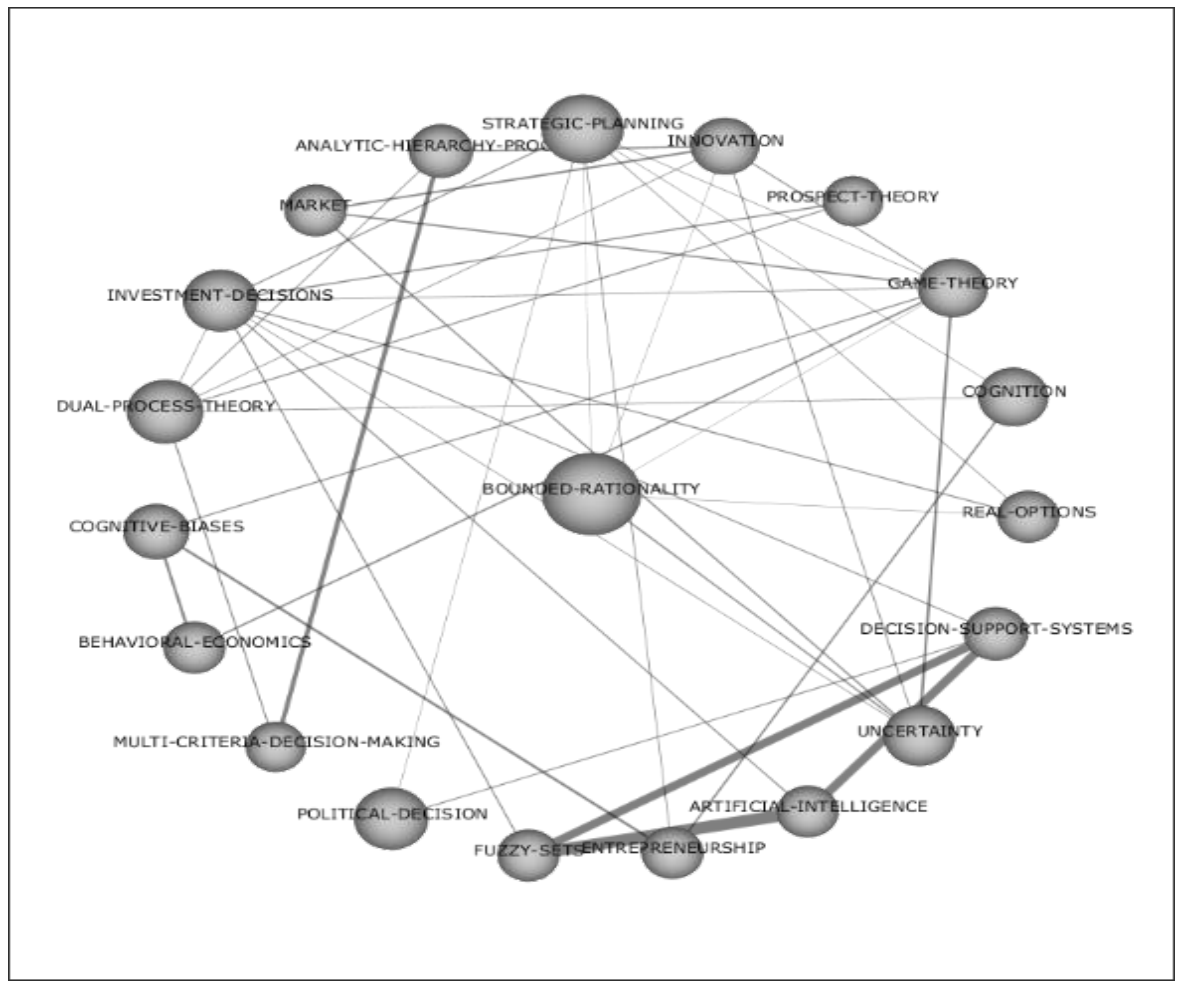

Figure 18: Cluster Network Using SciMAT 2005-2009 (bounded rationality)

influence towards other scientific themes given in the cluster network during the period of 2005 to 2009.

\subsubsection{The Scientific Mapping of Strategic Decision (2010-2014)}

To illustrate the analysis for the period 2010 to 2014, Figure 19 is provided. It highlights the most significant themes of the decisionmaking research field which comprised: decision-making, game theory, entrepreneurship, strategic planning and portfolio management. These scientific motor themes as shown in quadrant 1 of Figure 19 are relatively well developed and imperative for a given scientific field in a given period of time. The underdeveloped themes shown in quadrant 2 comprised: strategic decision, mental models, projects, real option, and tacit knowledge. They are relatively important but weakly structured. 


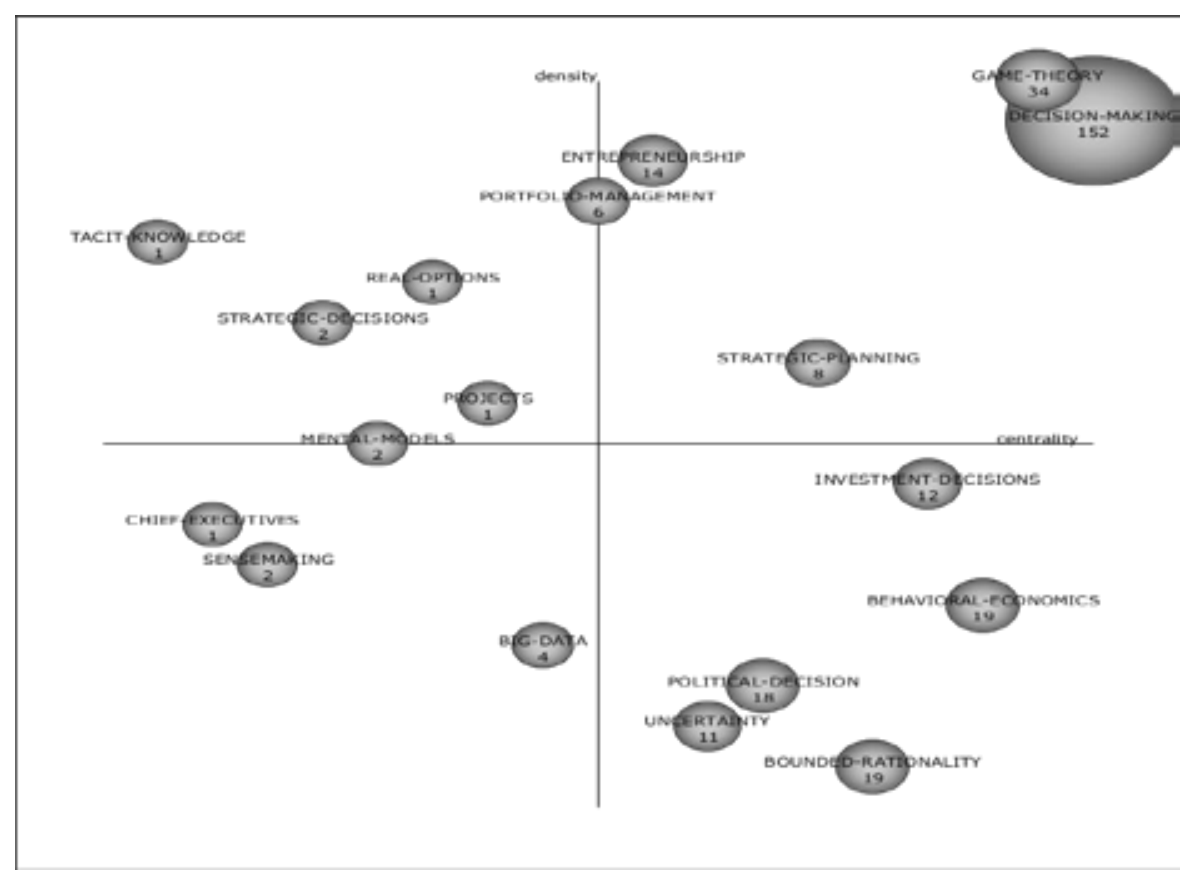

Figure 19: Strategic Map Diagram Using SciMAT 2010-2014 (secondary document counts)

The declining themes such as big data, sense-making and chief executive can be found in quadrant 3 . Both are inadequately developed and marginal topics, representing the emerging topics in the age of industrial fourth revolution. Finally, the basic and transversal themes such as: behavioural economics, bounded rationality, political decision, investment decision, and uncertainty are illustrated in quadrant 4 . They are well-developed internal links but they have marginal external ties.

To highlight the fuzzy sets, Figure 20 is provided. According to the cluster network, the fuzzy sets have the largest network. It is also mainly associated with prominent scientific themes such as: artificial intelligence, multi-criteria decision-making, and decision support system. The rest of the cluster network consists of minor scientific themes such as: prospect theory, cognition, and game theory. The findings reveal that the decision support system plays a vital role in the scientific themes. It has a powerful influence on other scientific themes such as those given in cluster network during the period of 2010 to 2014. 


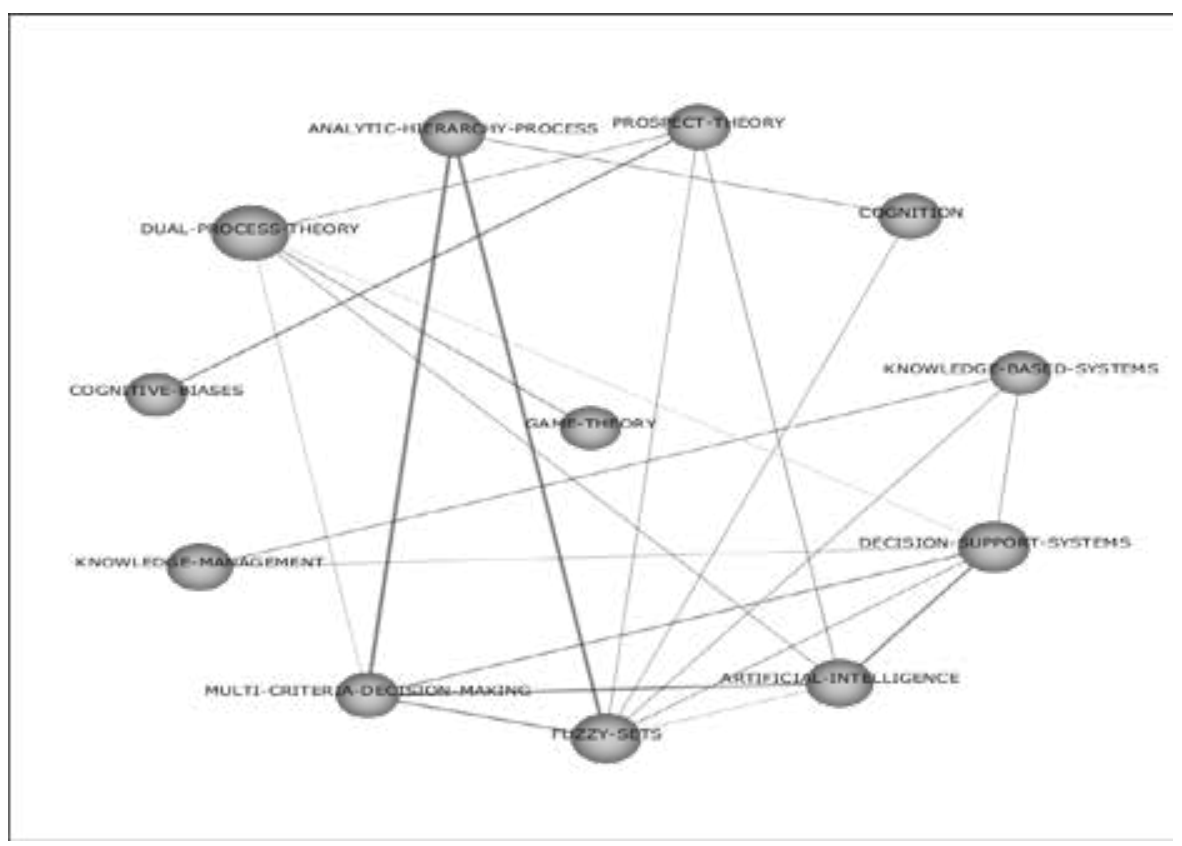

Figure 20: Cluster Network Using SciMAT 2010-2014 (decision support system)

\subsubsection{The Scientific Mapping of Strategic Decision (2015-2018)}

Figure 21 is provided to explain this section. During the period between 2015 and 2018, the most important themes of the decisionmaking research field are intuition, bounded rationality, cognition and innovation. These scientific motor themes shown in quadrant 1 are relatively well developed and imperative for a given scientific field in a given period of time. The transversal or underdeveloped themes are shown in quadrant 2 are relatively important but weakly structured: three-way decision, analytic hierarchy process and new product development. These considerable themes are classified to be transversal topics or underdeveloped topics of considerable significance for the entire research field.

The declining themes such as leadership, psychological bias and market can be found in quadrant 3 which are both inadequately developed and marginal topics, representing emerging topics in the age of industrial fourth revolution. Lastly, the basic and transversal themes such as political decision, uncertainty and entrepreneurship can 


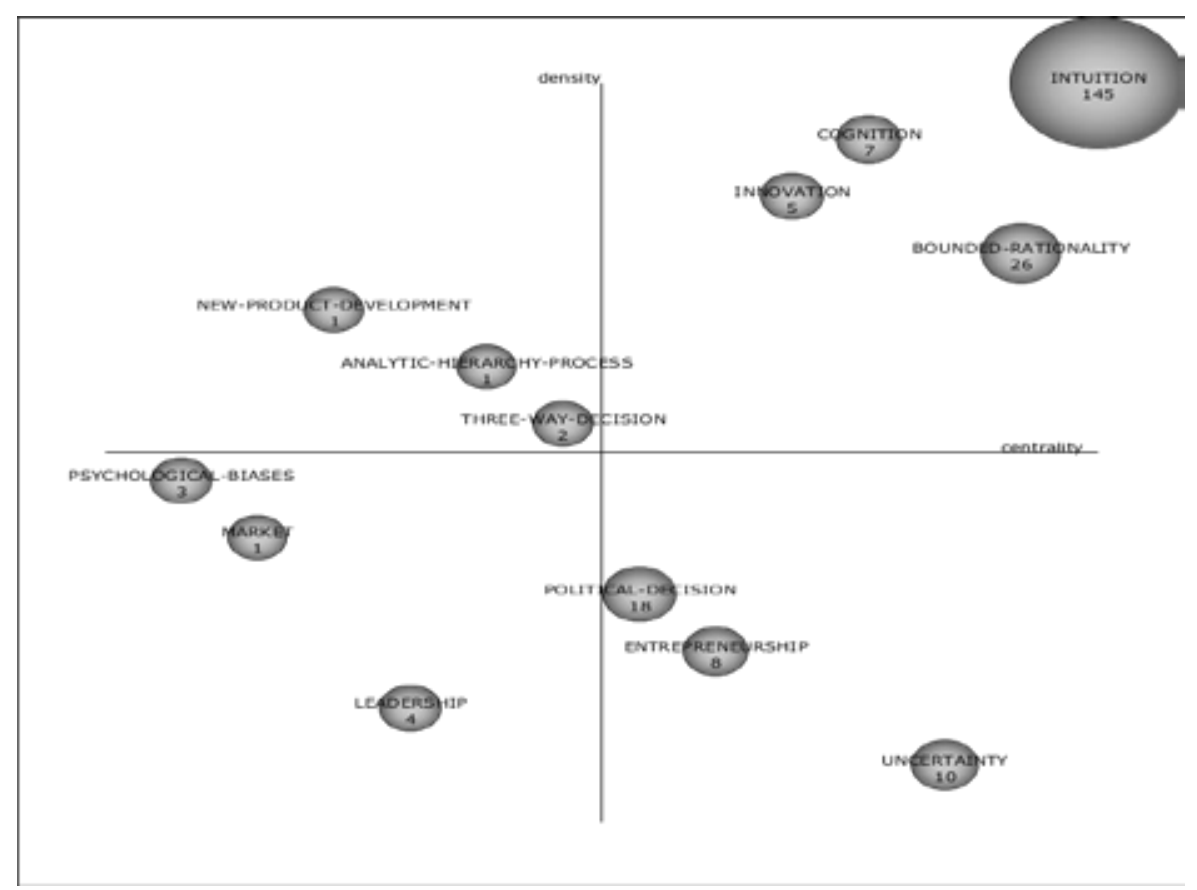

Figure 21: Strategic Map Diagram Using SciMAT 2015-2018 (secondary document counts)

be found in quadrant 4 . These particular themes are well-developed internal links but they have marginal external ties. According to the cluster network of Figure 22, the largest network on research involving decision-making is mainly associated with prominent scientific themes such as: behavioural economics, intuition, rationality and dual process theory. The rest of the clusters consist of minor scientific themes such as: fuzzy sets, big data, investment decision, multi-criteria decision-making, strategic planning and game theory. The findings revealed that decisionmaking plays a vital role in the scientific themes. It also has a powerful influence on other scientific themes such as those given in the cluster network during the period of 2015 and 2018.

The findings further reveal the thematic focus for each of the time periods. For instance, decision-making and intuition for 2000 to 2004, bounded rationality and uncertainty for 2005-2009, decision support system and artificial intelligence for 2010 to 2014, and decision-making and intuition for 2015 to 2019. Overall, it can be summarised that 


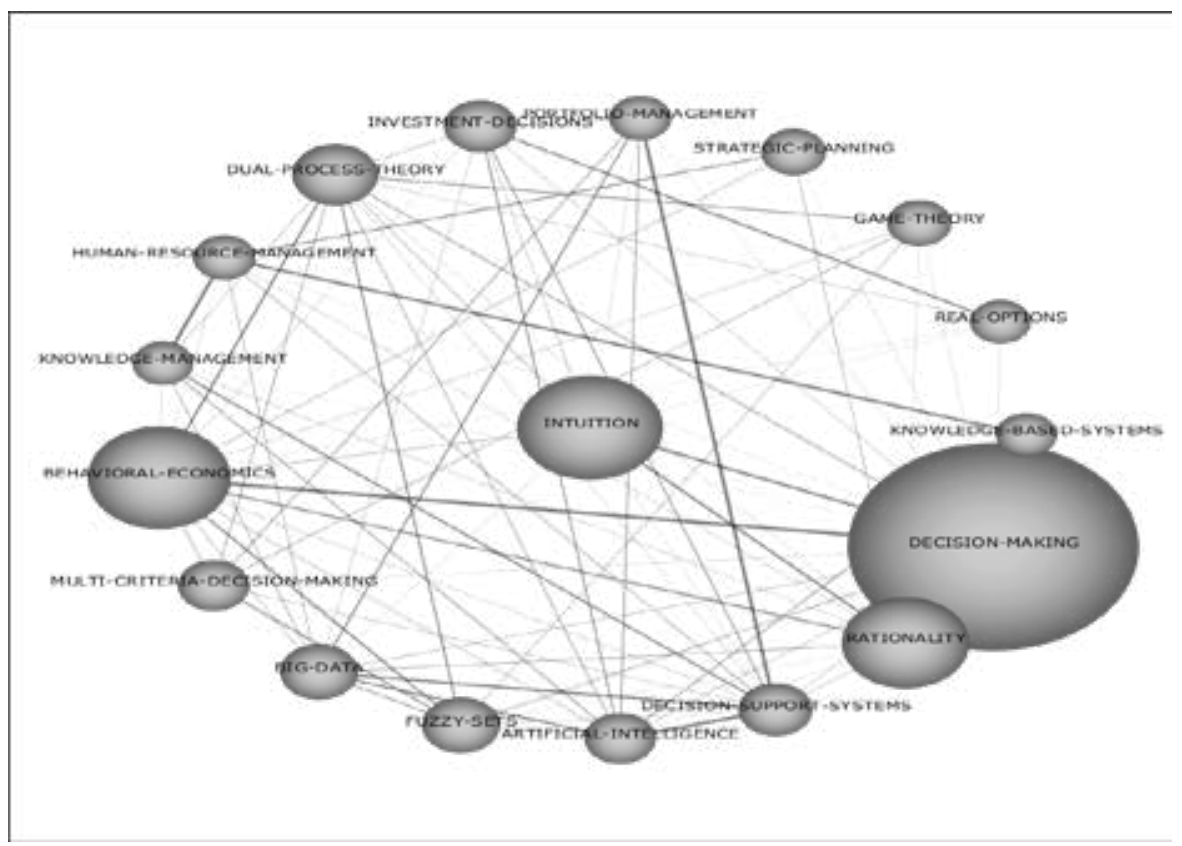

Figure 22: Cluster Network Using SciMAT 2015-2018 (decision-making)

the top co-wordings, based on centrality from 1971 to 2018 include: decision-making, intuition, rationality, behavioural economics, bounded rationality and investment decision. Further, the prominent themes based on centrality range include: decision-making, intuition, rationality, behavioural economics and decision support system. The top five themes based on density range include: knowledge-based systems, information, tacit knowledge, new product development and strategic decisions.

Once the keywords' evolution was analysed, we then evaluated the scientific evolutionary themes of strategic decision-making field through the thematic areas (see Figure 23). Many of the results achieved in this epigraph confirmed the initial evolution we had highlighted. Initially, research was related to how the decision was made in a given process - intuition, rationality and political decision (decision-making, intuition, rationality, political decision). This outcome was derived based on specific tools such as: the decision support system, fuzzy sets, and artificial intelligence (decision support system, fuzzy sets, artificial intelligence) based on a condition of uncertainty and the cognitive constraint of bounded rationality (uncertainty, bounded rationality). 


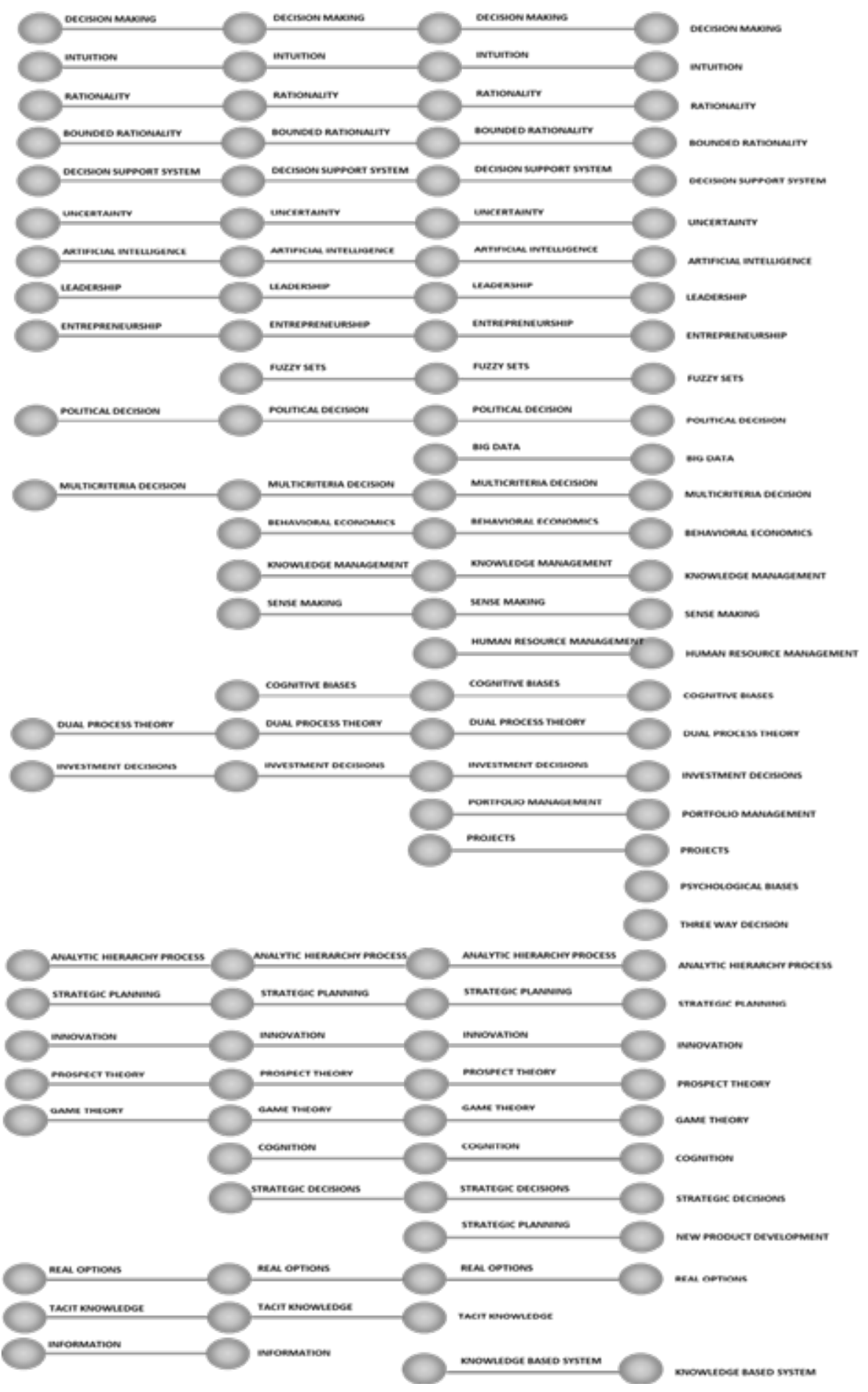

Figure 23: Longitudinal Analysis Based on Core Document H Index Using SciMAT 2017-2018 
According to the evolution map shown in Figure 23, the emerging themes comprised: behavioural economics, knowledge management, sensemaking, strategic decisions, cognition and portfolio management. In contrast, the disappearing themes were related to: information, market, tacit knowledge and chief executives. According to the h-index, some of the most attractive studies carried various scientific themes such as: decision-making, intuition, rationality, bounded rationality, decision support system, artificial intelligence, leadership, entrepreneurship, fuzzy sets and political decision. It appears that the thickness of the edges is proportional to the Inclusion Index, and the volume of the spheres is proportional to the number of published documents associated with each cluster (Alcaide-Muñoz et al., 2017). The findings also denoted the emerging scientific themes to be: fuzzy sets, big data, behavioural economics, knowledge management, sensemaking, human resource management, cognitive biases, portfolio management, projects, psychological biases, three-way decision, cognition, strategic decisions, new product development and knowledge based systems.

\section{Conclusions and Implications}

\subsection{Contributions}

Our study has provided a systematic and updated review of past studies which focussed on SD. In this regard, we also pursued a longitudinal study which embraced four time periods from 1971 to 2018, covering a span of 48 years. Our results depict a long list of taxonomy, highlighting the evolution of research on SD in the field of business and management. Our findings reveal the huge shift in the study of SD, especially over the past ten years. The results depict a gradual increase in the number of studies published in international scientific journals since 2000 and the peak of the publication was between 2010 to 2018 .

From our review and detailed analysis, several outcomes are generated. First, the Sankey Diagram illustrated the intellectual structure of the authors, co-wordings and scientific publishing journals. The line's thickness and its interdependency reflected the strong connection among the given scientific terms. We also analysed the multi-dimensional aspect of the bibliometric datasets such as: authorships (Elbanna, Parayitam, Cray, Dooley and Amason), co-wording terms (decision making, strategic decision making, strategy, strategic decision-making, and strategic management), publishing journals (Management Decision, 
Strategic Management Journal, Long Range Planning, Journal of Business Research and Decision Support System).

The Sankey Diagram illustrated the gap between the prolific scholars, and the existing key wording profiles of a given sector or subsector of SD research. This difference of the lines' thickness reflecting the inter-linkages and the inter-dependencies of the keywords, thus served as a basis for further evaluation of the field of research (Subramanyam et al., 2015). Meanwhile, the most cited papers were found to introduce both the emerging theories and perspectives, and this seems to change the direction of the research (Ferreira et al., 2016). In order to deepen our understanding, we suggest the development of new theories from the rational perspective to the incremental perspective in the development of SD research in the field of business and management research.

Additionally, the scientific networks and cluster trends shown in the VOSviewer have also displayed the evolution of SD research in business and management from 1971 to 2018. The decision-making processes had evolved in diverse ways, moving from analytical hierarchy processes to fuzzy logic, decision support system, rationality, intuition, political decision (part of behavioural research), data analytics, and artificial intelligence. The clusters shows that decisionmaking as a research theme, have been investigated within the wide context of business and management, for instance, 'strategic planning', 'supply chain management', 'manufacturing', 'product development', 'investment', 'marketing', and 'industrial management'.

Finally, the strategic diagrams and performance measures shown in the SciMAT reveal some of the most significant themes of strategic decision-making in the field of business and management from 1971 to 2018. They include: 'decision-making', 'intuition', 'rationality', 'bounded rationality', 'decision support system', 'dual process theory' and 'political decision'. According to the results shown in each subtime period, some of the most important themes that had emerged in the decision-making research field were: 'decision-making' and 'intuition' (2000-2004), 'bounded rationality' and 'uncertainty' (20052009), 'decision support system' and 'artificial intelligence' (20102014), followed by 'decision-making' and 'intuition' (2015-2019). From the centrality and density of the results generated, some of the most important themes that had surfaced in the decision-making research field were: 'decision-making', 'intuition', 'rationality', 'bounded rationality' and 'decision support system'. 
Grounded on the results derived from the bibliometric mapping analysis, it is also observed that some of the scientific themes of SD that carried the highest number of publications and citational measures were: 'intuition', 'rationality', 'bounded rationality' and 'decision support system'. We also found a high number of new and transient keywords within the time period we selected, for instance, 'behavioural economics', 'knowledge management', 'sense making', 'strategic decisions', 'cognition' and 'portfolio management'. They signify that the research on strategic decision-making has not reached a period of maturity yet.

\subsection{Recommendation for Future Research}

The recommendation approach adopted by previous studies had used certain emerging and discontinued themes, as depicted in the SciMAT (Alcaide-Muñoz et al., 2017; Cobo et al., 2011, 2012). In this study, our findings have stressed on the importance of addressing some forthcoming works that could provide implications and directions for future research. Over the years of studies conducted, academics and scholars have observed that very few studies have focussed on behavioural economics and knowledge management. Based on this lack, it is imperative to know the relationship of these themes on decisionmaking. For instance, how are behavioural features highlighted for making strategic decisions? What kind of problems and risks can influence the making of strategic decisions in the field of portfolio management?

Next, it appears that future research needs to explore the discontinued themes of information, market and tacit knowledge because they are still relevant in today's world. This can be accomplished by empirical research that evaluates how those relationships impact on decision-making. In addition, it is also necessary to understand if there were any difficulties involved when decision-makers applied their tacit knowledge in making strategic decisions. This may also raise issues on the kind of information used by decision makers to effectively make their strategic decisions. From this, various problems obstructing the effective use of information for SD research can be revealed.

Further to the above implications, it seems imperative for future regional or global analysis to be performed by taking into account the context of emerging countries, instead of merely focussing on particular fields such as business and management research. By com- 
bining the research on SD with other fields, a more holistic analysis in understanding interdisciplinary perspectives of SD research can be accomplished. From this standpoint, it may also enrich queries and keywords which can further reveal the diverse scientific themes of decision-making (Cobo, Jürgens, Herrero-Solana, Martínez, \& HerreraViedma, 2018).

Finally, the evolution of the research themes could be studied by using other scientific tools such as the Web of Science (WoS) as one approach to expand on the articles published. It is one of the most imperative bibliographic datasets applied over the last ten years (Cobo et al., 2018).

\subsection{Limitation of the Study}

In spite of the evidence generated in this study to support our conclusion and implications, this study is also constrained in some ways. First and foremost, the complex nature of the SD process used within an interdisciplinary research serves as the limitation, particularly in the selection of datasets (Nooraie, 2008).

Second, by focusing only on the Scopus retrieval system, this study is also restricted by publications of different sources. In reality, many articles related to SD had also been published beyond the Scopus retrieval system.

Third, our selection of articles zoomed in on business and management issues only. Other datasets from diverse perspectives, and empirical works with different contexts and settings were thus overlooked. Therefore, even though our findings had reported on the taxonomy and evolution of SD over a long-time frame, our evidence was restrictive in some ways. Multiple datasets extracted from diverse and complex fields of study would be more generalisable.

Fourth, our datasets were gathered using key terms and the Boolean logic of keywords in either the title or abstracts only. This kind of limitation is common in bibliometric studies (Chen, Chiang, \& Storey, 2012), hence there is a need to concentrate on this gap for interpretability and generalisability of the findings. Nonetheless, despite the limitations, our findings had visualised the intellectual structure and evolution of strategic decision in the field of business and management. Future research may consider assessing the generalisability of these findings by implementing the approach on different situations and settings. 


\section{References}

Akinci, C., \& Sadler-Smith, E. (2012). Intuition in management research: A historical review. International Journal of Management Reviews, 14(1), 104-122. http://dx.doi.org/10.1111/j.1468-2370.2011.00313.x

Alcaide-Muñoz, L., Rodríguez-Bolívar, M.P., Cobo, M.J., \& Herrera-Viedma, E. (2017). Analysing the scientific evolution of e-government using a science mapping approach. Government Information Quarterly, 34(3), 545-555. http://dx.doi.org/10.1016/j.giq.2017.05.002

Amason, A.C. (1996). Distinguishing the effects of functional and dysfunctional conflict on strategic decision making: Resolving a paradox for top management teams. Academy of Management Journal, 39(1), 123-148. http://dx.doi. org $/ 10.5465 / 256633$

Baldacchino, L., Ucbasaran, D., \& Cabantous, L. (2014). Experience and opportunity identification: The role of intuition and cognitive versatility. Academy of Management Proceedings, 2014(1), 17303-17303. http://dx.doi. org/10.5465/ambpp.2014.17303abstract

Bingham, C.B., \& Eisenhardt, K.M. (2011). Rational heuristics: The 'simple rules' that strategists learn from process experience. Strategic Management Journal, 32(13), 1437-1464. http://dx.doi.org/10.1002/smj.965

Blanco-Mesa, F., Merigó, J.M., \& Gil-Lafuente, A.M. (2017). Fuzzy decision making: A bibliometric-based review. Journal of Intelligent \& Fuzzy Systems, 32(3), 2033-2050. http:/ / dx.doi.org/10.3233/JIFS-161640

Bourgeois, L.J., \& Eisenhardt, K.M. (1988). Strategic decision processes in high velocity environments: Four cases in the microcomputer industry. Management Science, 34(7), 816-835. http://dx.doi.org/10.1287/mnsc.34.7.816

Bragge, J., Korhonen, P., Wallenius, H., \& Wallenius, J. (2010). Bibliometric analysis of multiple criteria decision making/multiattribute utility theory. In M. Ehrgott, B. Naujoks, T. Stewart, \& J. Wallenius (Eds.), Multiple Criteria Decision Making for Sustainable Energy and Transportation Systems (pp. 259268). Berlin, Heidelberg: Springer. http://dx.doi.org/10.1007/978-3-64204045-0_22

Brockmann, E.N., \& Simmonds, P.G. (1997). Strategic decision making: The influence of CEO experience and use of tacit knowledge. Journal of Managerial Issues, 9(4), 454-467.

Castillo-Vergara, M., Alvarez-Marin, A., \& Placencio-Hidalgo, D. (2018). A bibliometric analysis of creativity in the field of business economics. Journal of Business Research, 85(April), 1-9. http://dx.doi.org/10.1016/j. jbusres.2017.12.011

Chen, H., Chiang, R.H.L., \& Storey, V.C. (2012). Business intelligence and analytics: From big data to big impact. MIS Quarterly, 36(4). 1165-1188. http://dx.doi.org/10.2307/41703503

Cobo, M.J., López-Herrera, A.G., Herrera-Viedma, E., \& Herrera, F. (2011). Science mapping software tools: Review, analysis, and cooperative study 
among tools. Journal of the American Society for Information Science and Technology, 62(7), 1382-1402. http:// dx.doi.org/10.1002/asi.21525

Cobo, M.J., López-Herrera, A.G., Herrera-Viedma, E., \& Herrera, F. (2012). SciMAT: A new science mapping analysis software tool. Journal of the American Society for Information Science and Technology, 63(8), 1609-1630. http://dx.doi.org/10.1002/asi.22688

Cobo, M.J., Jürgens, B., Herrero-Solana, V., Martínez, M.A., \& Herrera-Viedma, E. (2018). Industry 4.0: A perspective based on bibliometric analysis. Procedia Computer Science, 139, 364-371. http://dx.doi.org/10.1016/j.procs. 2018.10.278

Dane, E., \& Pratt, M.G. (2007). Exploring intuition and its role in managerial decision making. Academy of Management Review, 32(1), 33-54. http:// dx.doi.org/10.5465/amr.2007.23463682

Dean, J.W., \& Sharfman, M.P. (1993). The relationship between procedural rationality and political behaviour in strategic decision making. Decision Sciences, 24(6), 1069-1083. http://dx.doi.org/10.1111/j.1540-5915.1993.tb 00504.x

Dean, J.W., \& Sharfman, M.P. (1996). Does decision process matter? A study of strategic decision-making effectiveness. Academy of Management Journal, 39(2), 368-392. http://dx.doi.org/10.5465/256784

Eisenhardt, K.M. (1989). Making fast strategic decisions in high-velocity environments. Academy of Management Journal, 32(3), 543-576. http://dx.doi.org/ $10.5465 / 256434$

Eisenhardt, K.M., \& Martin, J.A. (2000). Dynamic capabilities: What are they? Strategic Management Journal, 21(10-11), 1105-1121. http://dx.doi. org/10.1002/1097-0266(200010/11)21:10/11\%3C1105::AID-SMJ133\%3E3.0. $\mathrm{CO} ; 2-\mathrm{E}$

Eisenhardt, K.M., \& Zbaracki, M.J. (1992). Strategic decision making. Strategic Management Journal, 13(S2), 17-37. http://dx.doi.org/10.1002/smj.42501 30904

Elbanna, S. (2006). Strategic decision-making: Process perspectives. International Journal of Management Reviews, 8(1), 1-20. http:// dx.doi.org/10.1111/j.14682370.2006.00118.x

Elbanna, S. (2018). The constructive aspect of political behavior in strategic decision-making: The role of diversity. European Management Journal, 36(5), 616-626. http://dx.doi.org/10.1016/j.emj.2018.06.006

Elbanna, S., \& Child, J. (2007). Influences on strategic decision effectiveness: Development and test of an integrative model. Strategic Management Journal, 28(4), 431-453. http:/ / dx.doi.org/10.1002/smj.597

Elbanna, S., Kapoutsis, I., \& Mellahi, K. (2017). Creativity and propitiousness in strategic decision making: The role of positive politics and macro-economic uncertainty. Management Decision, 55(10), 2218-2236. http://dx.doi.org/ 10.1108/MD-02-2017-0113 
Elbanna, S., \& Younies, H. (2008). The relationships between the characteristics of the strategy process: Evidence from Egypt. Management Decision, 46(4), 626-639. http:/ / dx.doi.org/10.1108/00251740810865094

Epstein, S. (1985). The implications of cognitive-experiential self-theory for research in social psychology and personality. Journal for the Theory of Social Behaviour, 15(3), 283-310. http://dx.doi.org/10.1111/j.1468-5914.1985.tb 00057.x

Fahey, L. (1981). On strategic management decision processes. Strategic Management Journal, 2(1), 43-60. http:// dx.doi.org/10.1002/smj.4250020105

Ferreira, J.J.M., Fernandes, C.I., \& Ratten, V. (2016). A co-citation bibliometric analysis of strategic management research. Scientometrics, 109(1), 1-32. http://dx.doi.org/10.1007/s11192-016-2008-0

Finkelstein, S. (1992). Power in top management teams: Dimensions, measurement, and validation. Academy of Management journal, 35(3), 505-538. http://dx.doi.org/10.5465/256485

Forbes, D.P., \& Milliken, F.J. (1999). Cognition and corporate governance: Understanding boards of directors as strategic decision-making groups. Academy of Management Review, 24(3), 489-505. http://dx.doi.org/10.5465/ amr.1999.2202133

Heradio, R., Perez-Morago, H., Fernandez-Amoros, D., Cabrerizo, F.J., \& Herrera-Viedma, E. (2016). A bibliometric analysis of 20 years of research on software product lines. Information and Software Technology, 72(April), 1-15. http://dx.doi.org/10.1016/j.infsof.2015.11.004

Hodgkinson, G.P., Langan-Fox, J., \& Sadler-Smith, E. (2008). Intuition: A fundamental bridging construct in the behavioural sciences. British Journal of Psychology, 99(1), 1-27. http://dx.doi.org/10.1348/000712607X216666

Hodgkinson, G.P., Sadler-Smith, E., Burke, L.A., Claxton, G., \& Sparrow, P.R. (2009). Intuition in organizations: Implications for strategic management. Long Range Planning, 42(3), 277-297. http://dx.doi.org/10.1016/j.lrp.2009. 05.003

Ireland, R.D., \& Miller, C.C. (2004). Decision-making and firm success. Academy of Management Perspectives, 18(4), 8-12. http://dx.doi.org/10.5465/ame. 2004.15268665

Isenberg, D.J. (1986). Thinking and managing: A verbal protocol analysis of managerial problem solving. Academy of Management Journal, 29(4), 775-788. http://dx.doi.org/10.5465/255944

Kahneman, D., \& Tversky, A. (1979). Prospect theory: An analysis of decision under risk. Econometrica, 47(2), 263-291. http://dx.doi.org/10.2307/1914185

Keats, B.W. (1991). An empirical investigation of strategic investment decision models. Strategic Management Journal, 12(3), 243-250. http://dx.doi.org/ 10.1002/smj.4250120307

Khatri, N., \& Ng, H.A. (2000). The role of intuition in strategic decision making. Human Relations, 53(1), 57-86. http://dx.doi.org/10.1177\%2F0018726700 531004 
Klein, G. (1998). Sources of power: How people make decisions. Cambridge, MA: MIT Press.

Lant, T.K., Milliken, F.J., \& Batra, B. (1992). The role of managerial learning and interpretation in strategic persistence and reorientation: An empirical exploration. Strategic Management Journal, 13(8), 585-608. http://dx.doi. org/10.1002/smj.4250130803

Lumpkin, G.T., \& Dess, G.G. (2001). Linking two dimensions of entrepreneurial orientation to firm performance: The moderating role of environment and industry life cycle. Journal of Business Venturing, 16(5), 429-451. http:// dx.doi.org/10.1016/S0883-9026(00)00048-3

Lupton, R.C., \& Allwood, J.M. (2017). Hybrid Sankey diagrams: Visual analysis of multidimensional data for understanding resource use. Resources, Conservation and Recycling, 124(September), 141-151. http://dx.doi.org/ 10.1016/j.resconrec.2017.05.002

Merigó, J.M., Pedrycz, W., Weber, R., \& de la Sotta, C. (2018). Fifty years of information sciences: A bibliometric overview. Information Sciences, 432(March), 245-268. http:/ /dx.doi.org/10.1016/j.ins.2017.11.054

Miller, K.D., \& Shapira, Z. (2004). An empirical test of heuristics and biases affecting real option valuation. Strategic Management Journal, 25(3), 269-284. http:/ /dx.doi.org/10.1002/smj.374

Mintzberg, H., Raisinghani, D., \& Theoret, A. (1976). The structure of 'unstructured' decision processes. Administrative Science Quarterly, 21(2), 246-275. http:/ / dx.doi.org/10.2307/2392045

Nerur, S.P., Rasheed, A.A., \& Natarajan, V. (2008). The intellectual structure of the strategic management field: An author co-citation analysis. Strategic Management Journal, 29(3), 319-336. http:/ /dx.doi.org/10.1002/smj.659

Nooraie, M. (2008). Decision magnitude of impact and strategic decision-making process output: The mediating impact of rationality of the decision-making process. Management Decision, 46(4), 640-655. http://dx.doi.org/10.1108/ 00251740810865102

Papadakis, V.M., Lioukas, S., \& Chambers, D. (1998). Strategic decision-making processes: The role of management and context. Strategic Management Journal, 19(2), 115-147. http:/ /dx.doi.org/10.1002/(SICI)1097-0266(199802) 19:2\%3C115::AID-SMJ941\%3E3.0.CO;2-5

Qaiser, F.H., Ahmed, K., Sykora, M., Choudhary, A., \& Simpson, M. (2017). Decision support systems for sustainable logistics: A review and bibliometric analysis. Industrial Management $\mathcal{E}$ Data Systems, 117(7), 1376-1388. http://dx.doi.org/10.1108/IMDS-09-2016-0410

Rajagopalan, N., Rasheed, A.M., \& Datta, D.K. (1993). Strategic decision processes: Critical review and future directions. Journal of Management, 19(2), 349-384. http:/ / dx.doi.org/10.1016/0149-2063(93)90057-T

Ramos-Rodríguez, A.R., \& Ruíz-Navarro, J. (2004). Changes in the intellectual structure of strategic management research: A bibliometric study of the Strategic Management Journal, 1980-2000. Strategic Management Journal, 25(10), 981-1004. http:/ /dx.doi.org/10.1002/smj.397 
Ronda-Pupo, G. A., \& Guerras-Martin, L. Á. (2012). Dynamics of the evolution of the strategy concept 1962-2008: A co-word analysis. Strategic Management Journal, 33(2), 162-188. http:/ / dx.doi.org/10.1002/smj.948

Sadler-Smith, E., Hodgkinson, G.P., \& Sinclair, M. (2008). Chapter 2 A matter of feeling? The role of intuition in entrepreneurial decision-making and behavior. Emotions, Ethics and Decision-making, 4, 35-55. http://dx.doi. org/10.1016/S1746-9791(08)04002-9

Sadler-Smith, E., \& Shefy, E. (2004). The intuitive executive: Understanding and applying 'gut feel' in decision-making. Academy of Management Perspectives, 18(4), 76-91. http://dx.doi.org/10.5465/ame.2004.15268692

Sarkis, J. (2003). A strategic decision framework for green supply chain management. Journal of Cleaner Production, 11(4), 397-409. http://dx.doi. org/10.1016/S0959-6526(02)00062-8

Schmidt, F. (2008). Meta-analysis: A constantly evolving research integration tool. Organizational Research Methods, 11(1), 96-113. http://dx.doi. org/10.1177\%2F1094428107303161

Simon, H.A. (1987). Making management decisions: The role of intuition and emotion. Academy of Management Perspectives, 1(1), 57-64. http://dx.doi. org/10.5465/ame.1987.4275905

Soundararajan, K., Ho, H.K., \& Su, B. (2014). Sankey diagram framework for energy and exergy flows. Applied Energy, 136(December), 1035-1042. http://dx.doi.org/10.1016/j.apenergy.2014.08.070

Steptoe-Warren, G., Howat, D., \& Hume, I. (2011). Strategic thinking and decision making: Literature review. Journal of Strategy and Management, 4(3), 238-250. http://dx.doi.org/10.1108/17554251111152261

Subramanyam, V., Paramshivan, D., Kumar, A., \& Mondal, M.A.H. (2015). Using Sankey diagrams to map energy flow from primary fuel to end use. Energy Conversion and Management, 91(February), 342-352. http://dx.doi. org/10.1016/j.enconman.2014.12.024

Swamidass, P.M., \& Newell, W.T. (1987). Manufacturing strategy, environmental uncertainty and performance: A path analytic model. Management Science, 33(4), 509-524. http://dx.doi.org/10.1287/mnsc.33.4.509

Tranfield, D., Denyer, D., \& Smart, P. (2003). Towards a methodology for developing evidence-informed management knowledge by means of systematic review. British Journal of Management, 14(3), 207-222. http:// dx.doi.org/10.1111/1467-8551.00375

van Eck, N., \& Waltman, L. (2009). Software survey: VOSviewer, a computer program for bibliometric mapping. Scientometrics, 84(2), 523-538. http:// dx.doi.org/10.1007/s11192-009-0146-3

Yu, D., Wang, W., Zhang, W., \& Zhang, S. (2018). A bibliometric analysis of research on multiple criteria decision making. Current Science, 114(4), 747758. http://dx.doi.org/10.18520/cs/v114/i04/747-758

Zupic, I., \& Čater, T. (2015). Bibliometric methods in management and organization. Organizational Research Methods, 18(3), 429-472. http://dx.doi. org/10.1177\%2F1094428114562629 
